\title{
A heuristic reference recursive recipe for adaptively tuning the Kalman filter statistics part-2: real data studies
}

\author{
M SHYAM MOHAN ${ }^{1}$, NAREN NAIK ${ }^{2}$, R M O GEMSON ${ }^{3}$ and M R ANANTHASAYANAM ${ }^{4}$,* \\ ${ }^{1}$ Indian Institute of Technology, Kanpur, India \\ ${ }^{2}$ Department of Electrical Engineering, Indian Institute of Technology, Kanpur, India \\ ${ }^{3}$ Hindustan Aeronautics Limited, Bangalore, India \\ ${ }^{4}$ Department of Aerospace Engineering, Indian Institute of Science, Bangalore, India \\ e-mail: shyammoh.2014@iitkalumni.org; nnaik@iitk.ac.in; mogratnam@rediffmail.com; \\ sayanam2005@yahoo.co.in
}

MS received 29 April 2015; revised 16 March 2016; accepted 3 June 2016

\begin{abstract}
In part-1 of this paper an adaptive filtering based on a reference recursive recipe (RRR) was developed and tested on a simulated dynamics of a spring, mass and damper with a weak nonlinear spring. In this paper the above recipe is applied to a more involved case of three sets of airplane data that have a larger number of state, measurements and unknown parameters. The flight tests cannot always be conducted in an ideal situation of the process noise and the measurement noises being white Gaussian as is generally assumed in the Kalman filter. The measurements may not be available with respect to the center of gravity and possess scale and bias factors, which will have to be modelled and estimated as well. The coupling between the longitudinal and lateral motion brings in added difficulty but makes the problem more interesting. It turns out that even a parameter that strongly affects the airplane dynamics is estimated which vary widely among the approaches. The RRR has been shown to be better than the earlier approaches in estimating the unknowns. The generalized cost functions that are introduced in the present work help identify definitive results from deceptive results.
\end{abstract}

Keywords. Adaptive EKF; longitudinal and lateral flight dynamics; recursive parameter estimation; Cramer Rao bound.

\section{Introduction}

In part-1 of this paper an extensive study was carried out using an adaptive extended Kalman filter (EKF) tuning procedure called reference recursive recipe (RRR) applied to the simulated data of a simple spring, mass and damper system with a weak nonlinear spring. Here we demonstrate the effectiveness of the RRR in handling more involved flight test data of airplane longitudinal and lateral motion. They have many states and measurements and a large number of aerodynamic parameters to be estimated. Further the flight tests cannot always be conducted in an ideal situation of the process noise and the measurement noises being white Gaussian as assumed in the EKF. The measurements are not available with respect to the center of gravity and possess scale and bias factors, which will have to be modeled and estimated as well. The coupling between the longitudinal and lateral motion makes the problem difficult and thus more interesting. At times the noisy measurements from the longitudinal and lateral motion are input into the longitudinal states. This is another example of

*For correspondence subjectivity in estimation theory. However the final results should be meaningful and acceptable no matter whatever subjective inputs are introduced into the problem formulation and solution.

For airplane flight test data analysis many approaches have been suggested to handle unknown parameters and the noise covariances. These are the natural formulation of Schultz [1], the innovation formulation of Stepner and Mehra [2], a combined formulation called MMLE3 of Maine and Iliff [3, 4], the noise accounting approach of Jategaonkar and Plaetschke [5] and the combined formulation of Ishimoto [6] to solve the practical problems in natural and innovation formulations. A more detailed discussion on aircraft flight test data analysis can be found in Gemson [7], Klein and Morelli [8], Klein [9] and Jategaonkar [10]. There are many formulations for solving an optimization or estimation problem since the unknowns do not occur in a simple way in the cost function, and there are many transformed variables with which one tries to solve for the basic unknowns [11, 12]. Further the size and the required compatibility conditions among the transformed variables lead to the many difficulties not found in the classical optimization problems. 


\subsection{General observations from all the real fight test data results}

The report by Shyam et al [13] contains more examples of simulated and real flight test data analysis with down loadable computer programs and data for the benefit of the readers. Presently only three real flight data analysis is presented in this Part-2 of the paper.

All the real data studies were run for 100 iterations using the RRR with $\mathbf{Q}>0$ since the off-diagonal elements of the correlation coefficient matrix $C$ reduced substantially than for $\mathbf{Q}=0$ and hence all the former estimates are more reliable. The convergence of the parameter estimates, the noise covariances and the cost functions were analysed in terms of the quantities listed in section 6 of part- 1 of the paper.

Tables 1, 3 and 5 provide a comparison of the parameter estimates along with their CRBs for all the real data studied by different approaches. The cost functions and the $\mathbf{Q}$ and $\mathbf{R}$ estimates from RRR and other approaches are shown in tables 2, 4 and 6 for the three cases, respectively. Generally (but not always) the individual $\mathbf{R}$ and $\mathbf{Q}$ values are the least and the highest in RRR than from other approaches. However in all the cases firstly for the RRR approach the values of (i) $\mathbf{J 1}$ - J3 are closer to the number of measurements and the product of the estimated $\mathbf{R}$ is the smallest, indicating that the measurement equations are better balanced. Secondly the J6-J8 are closer to the number of states and the product of the estimated $\mathbf{Q}$ is the largest among all, thus assisting the state equations evolving with state noise to track the measurements better. Such a negatively correlated behaviour of $\mathbf{R}$ and $\mathbf{Q}$ is mentioned by Bohlin [14]. They show that the choice of the filter statistics for estimating $\mathbf{Q}$ and $\mathbf{R}$ in the proposed RRR approach is better than in other approaches.

Unlike in the simulated studies, in all cases it was noticed that the estimated $\mathbf{R}$ and $\mathbf{Q}$ noise did not have constant statistical characteristics across time. Another experiment was carried out by generating a typical data set by using the estimated parameter and injecting the estimated $\mathbf{Q}$ and $\mathbf{R}$ as additive white Gaussian noise. This is to determine the effect of non-white and non-Gaussian noise distribution in the real data on the CRBs. After each iteration in the RRR the $\Theta, \mathbf{Q}$ and $\mathbf{R}$ were reset as from the real data. A similar experiment was also conducted by updating $\Theta$ as well. It turned out that there is not much of a difference in the final estimates and the CRBs.

In the subsequent real data studies we use the notations and equations as in Gemson [7] and Gemson and Ananthasayanam [15].

Table 1. Real flight test data case-1 results $\left(\Theta, \sigma_{\Theta}\right)$.

\begin{tabular}{lccccc}
\hline$\Theta$ & RRR & NASA & Gemson & MT & MS \\
\hline$C_{N_{\alpha}}$ & $4.6469(0.0179)$ & $4.9584(0.1168)$ & $4.7073(0.039)$ & $4.6978(0.0229)$ & $4.9141(0.0422)$ \\
$C_{N_{\delta_{e}}}$ & $0.0555(0.0277)$ & $0.3023(0.1550)$ & $0.1292(0.0523)$ & $0.1225(0.0357)$ & $0.4691(0.0517)$ \\
$C_{L_{0}}$ & $0.0162(0.0032)$ & $0.2189(0.009344)$ & $-0.0064(0.0048)$ & $0.0160(0.0018)$ & $0.0184(0.0021)$ \\
$C_{m_{\alpha}}$ & $-0.5468(0.0093)$ & $-0.6125(0.00953)$ & $-0.63(0.0188)$ & $-0.5560(0.0098)$ & $-0.5885(0.0036)$ \\
$C_{m_{q}}$ & $-19.8027(0.6692)$ & $-22.27(0.7713)$ & $-20.8623(1.1908)$ & $-19.7062(0.7286)$ & $-20.2395(0.2937)$ \\
$C_{m_{\delta_{e}}}$ & $-1.1229(0.0218)$ & $-1.2193(0.02881)$ & $-1.2763(0.0442)$ & $-1.1396(0.0236)$ & $-1.1503(0.0111)$ \\
$C_{m_{0}}$ & $-0.0495(0.0012)$ & $-0.0532(0.00165)$ & $-0.0561(0.0023)$ & $-0.0502(0.0013)$ & $-0.0497(0.0006)$ \\
$\theta_{0}$ & $0.0007(0.0021)$ & $0.0273(0.04518)$ & $0.0007(0.0135)$ & $0.0008(0.0011)$ & $0.0003(0.0012)$ \\
$C_{N_{0}}$ & $0.2195(0.0014)$ & $0.2254(0.008725)$ & $0.2225(0.0029)$ & $0.2218(0.0018)$ & $0.2358(0.0028)$ \\
$C_{A_{\alpha}}$ & $-0.1398(0.0153)$ & $-0.3639(0.05328)$ & $-0.1023(0.0214)$ & $-0.1401(0.0185)$ & $0.1265(0.0197)$ \\
$C_{A_{\alpha^{2}}}$ & $-3.2088(0.1702)$ & $-(-)$ & $-3.2397(0.2430)$ & $-3.2088(0.2070)$ & $-3.8625(0.2376)$ \\
$C_{A_{\delta_{e}}}$ & $-0.0651(0.0134)$ & $-0.07(0.08084)$ & $-0.0267(0.0191)$ & $-0.0633(0.0160)$ & $-0.1178(0.0167)$ \\
$C_{A_{0}}$ & $-0.0155(0.0007)$ & $-0.0131(0.004088)$ & $-0.0144(0.0010)$ & $-0.0154(0.0008)$ & $-0.0182(0.0008)$ \\
\hline
\end{tabular}

Table 2. Real flight test data case-1 results ${ }^{\mathrm{a}}(\mathbf{R}, \mathbf{Q}, \mathbf{J})$.

\begin{tabular}{|c|c|c|c|c|c|c|c|c|}
\hline $\begin{array}{l}\mathbf{R} \text { (Ref) } \\
\times 10^{-6}\end{array}$ & $\begin{array}{l}\mathbf{Q} \text { (Ref) } \\
\times 10^{-6}\end{array}$ & $\begin{array}{c}\text { J1-J8 } \\
\text { (Ref) }\end{array}$ & $\begin{array}{c}\mathbf{R}(\mathrm{MT}) \\
\times 10^{-6}\end{array}$ & $\begin{array}{l}\mathbf{Q}(\mathrm{MT}) \\
\times 10^{-6}\end{array}$ & $\begin{array}{c}\text { J1-J8 } \\
(\mathrm{MT})\end{array}$ & $\begin{array}{c}\mathbf{R}(\mathrm{MS}) \\
\times 10^{-6}\end{array}$ & $\begin{array}{l}\mathbf{Q}(\mathrm{MS}) \\
\times 10^{-6}\end{array}$ & $\begin{array}{c}\mathbf{J 1}-\mathbf{J 8} \\
(\mathrm{MS})\end{array}$ \\
\hline & & 4.4752 & & & 4.0090 & & & 3.3893 \\
\hline 0.49 & & 5.1532 & 0.4107 & & 3.9630 & 3.2046 & & 3.3866 \\
\hline 0.04 & 0.134 & 4.6432 & 0.0312 & 0.0393 & 2.9764 & 37.6770 & 0.0001 & 3.2057 \\
\hline 0.40 & 2.287 & 0.0004 & 3.9381 & 2.6418 & 0.0004 & 7.5509 & 0.0015 & 0.0002 \\
\hline 15.98 & 1.204 & -56.2206 & 94.5086 & 0.3231 & -54.7596 & 198.2716 & 0.3456 & -49.6223 \\
\hline \multirow[t]{3}{*}{17.70} & & 2.9551 & 26.3511 & & 6.6681 & 28.9841 & & 3.8921 \\
\hline & & 2.9303 & & & 6.4985 & & & 4.7110 \\
\hline & & 2.5161 & & & 2.4562 & & & 2.6369 \\
\hline
\end{tabular}

${ }^{\mathrm{a}}$ Cost functions are not close to their expected values in MT and MS methods. 
Table 3. Real flight test data case- 2 results $\left(\Theta, \sigma_{\Theta}\right)$.

\begin{tabular}{|c|c|c|c|c|c|}
\hline$\Theta$ & RRR & NASA & Gemson & MT & MS \\
\hline$C_{L_{\alpha}}$ & $\begin{array}{c}4.9235 \\
(0.0164)\end{array}$ & $\begin{array}{c}5.1068 \\
(0.1322)\end{array}$ & $\begin{array}{c}4.9028 \\
(0.0168)\end{array}$ & $\begin{array}{c}4.9260 \\
(0.0184)\end{array}$ & $\begin{array}{c}5.0620 \\
(0.0323)\end{array}$ \\
\hline$C_{L_{\delta_{e}}}$ & $\begin{array}{c}0.1554 \\
(0.0271)\end{array}$ & $\begin{array}{c}0.1909 \\
(0.1602)\end{array}$ & $\begin{array}{c}0.0879 \\
(0.0267)\end{array}$ & $\begin{array}{c}0.1587 \\
(0.0302)\end{array}$ & $\begin{array}{c}0.3594 \\
(0.0508)\end{array}$ \\
\hline$C_{L_{0}}$ & $\begin{array}{c}0.2409 \\
(0.0021)\end{array}$ & $\begin{array}{c}0.2448 \\
(0.009215)\end{array}$ & $\begin{array}{c}0.2529 \\
(0.0018)\end{array}$ & $\begin{array}{c}0.2408 \\
(0.0023)\end{array}$ & $\begin{array}{c}0.2517 \\
(0.0027)\end{array}$ \\
\hline$C_{m_{\alpha}}$ & $\begin{array}{l}-0.5293 \\
(0.0079)\end{array}$ & $\begin{array}{c}-0.6474 \\
(0.02339)\end{array}$ & $\begin{array}{l}-0.6174 \\
(0.0211)\end{array}$ & $\begin{array}{c}-0.5285 \\
(0.0082)\end{array}$ & $\begin{array}{l}-0.5590 \\
(0.0055)\end{array}$ \\
\hline$C_{m_{q}}$ & $\begin{array}{c}-11.8596 \\
(0.2402)\end{array}$ & $\begin{array}{c}-14.26 \\
(0.6528)\end{array}$ & $\begin{array}{c}-18.8339 \\
(0.8379)\end{array}$ & $\begin{array}{c}-11.8255 \\
(0.2483)\end{array}$ & $\begin{array}{c}-12.5965 \\
(0.1400)\end{array}$ \\
\hline$C_{m_{\dot{\alpha}}}$ & $\begin{array}{c}-6.8959 \\
(0.4891)\end{array}$ & $\begin{array}{c}-8.27 \\
(1.296)\end{array}$ & $\begin{array}{c}-7.1290 \\
(1.544)\end{array}$ & $\begin{array}{c}-6.8798 \\
(0.5062)\end{array}$ & $\begin{array}{l}-6.6713 \\
(0.3021)\end{array}$ \\
\hline$C_{m_{\delta_{e}}}$ & $\begin{array}{l}-0.9731 \\
(0.0177)\end{array}$ & $\begin{array}{c}-1.1614 \\
(0.05371)\end{array}$ & $\begin{array}{c}-1.1841 \\
(0.471)\end{array}$ & $\begin{array}{l}-0.9711 \\
(0.0184)\end{array}$ & $\begin{array}{l}-1.0247 \\
(0.0129)\end{array}$ \\
\hline$C_{m_{0}}$ & $\begin{array}{l}-0.0425 \\
(0.0009)\end{array}$ & $\begin{array}{c}-0.0505 \\
(0.002655)\end{array}$ & $\begin{array}{l}-0.0507 \\
(0.0024)\end{array}$ & $\begin{array}{c}-0.0424 \\
(0.0009)\end{array}$ & $\begin{array}{l}-0.0447 \\
(0.0006)\end{array}$ \\
\hline$\theta_{0}$ & $\begin{array}{c}0.0003 \\
(0.0021)\end{array}$ & $\begin{array}{l}-0.01177 \\
(0.02528)\end{array}$ & $\begin{array}{c}-0.0037 \\
(0.001)\end{array}$ & $\begin{array}{c}0.0002 \\
(0.0011)\end{array}$ & $\begin{array}{l}-0.0006 \\
(0.0007)\end{array}$ \\
\hline$C_{N_{0}}$ & $\begin{array}{c}0.2538 \\
(0.0014)\end{array}$ & $\begin{array}{c}0.2541 \\
(0.008935)\end{array}$ & $\begin{array}{c}0.2503 \\
(0.0014)\end{array}$ & $\begin{array}{c}0.2540 \\
(0.0016)\end{array}$ & $\begin{array}{c}0.2635 \\
(0.0026)\end{array}$ \\
\hline
\end{tabular}

Table 4. Real flight test data case-2 results ${ }^{\mathrm{a}}(\mathbf{R}, \mathbf{Q}, \mathbf{J})$.

\begin{tabular}{|c|c|c|c|c|c|c|c|c|}
\hline $\begin{array}{l}\mathbf{R} \text { (Ref) } \\
\times 10^{-6}\end{array}$ & $\begin{array}{c}\mathbf{Q}(\mathrm{Ref}) \\
\times 10^{-6}\end{array}$ & $\begin{array}{c}\text { J1-J8 } \\
\text { (Ref) }\end{array}$ & $\begin{array}{c}\mathbf{R}(\mathrm{MT}) \\
\times 10^{-6}\end{array}$ & $\begin{array}{c}\mathbf{Q}(\mathrm{MT}) \\
\times 10^{-6}\end{array}$ & $\begin{array}{c}\text { J1-J8 } \\
\text { (MT) }\end{array}$ & $\begin{array}{c}\mathbf{R}(\mathrm{MS}) \\
\times 10^{-6}\end{array}$ & $\begin{array}{c}\mathbf{Q}(\mathrm{MS}) \\
\times 10^{-6}\end{array}$ & $\begin{array}{c}\text { J1-J8 } \\
(\mathrm{MS})\end{array}$ \\
\hline & & 3.9336 & & & & 3.7662 & & 3.1621 \\
\hline & & 4.2225 & & & & 4.5191 & & 3.1507 \\
\hline 1.241 & 0.180 & 3.6162 & 1.6135 & 0.2025 & 3.8384 & 3.1599 & 0.00005 & 2.5900 \\
\hline 0.051 & 2.954 & 0.0008 & 0.2395 & 3.1532 & 0.0008 & 37.2424 & 0.0003 & 0.0007 \\
\hline 0.460 & 2.646 & -44.1347 & 2.3155 & 0.6666 & -43.7340 & 9.3413 & 0.2386 & -38.0517 \\
\hline \multirow[t]{3}{*}{5.668} & & 2.9752 & 2.9290 & & 4.2266 & 841.5496 & & 8.4768 \\
\hline & & 2.9760 & & & 4.2284 & & & 8.4655 \\
\hline & & 2.9070 & & & 2.9489 & & & 3.0215 \\
\hline
\end{tabular}

${ }^{\mathrm{a}}$ Cost functions are not close to their expected values in MT and MS methods.

\section{Analysis of real flight test case-1}

The salient features of this aircraft are available in NASA TM-X 56036 [16] and in NASA TP 1690 [3]. The parameters are estimated in dimensionless form. The data set obtained is for a short period motion excited by the up and down elevator control input ( $\delta_{e}$ in degrees or 'deg') as shown in figure 1 . In general the flight test data are such that the longitudinal and lateral motions are decoupled. Some of the available measurements have been used as inputs in the state equations, which include roll angle $\left(\phi_{m}\right)$, sideslip $\left(\beta_{m}\right)$, roll rate $\left(p_{m}\right)$, yaw rate $\left(r_{m}\right)$ and the angle of attack $\left(\alpha_{m}\right)$ and are shown in figures $2,3,4,5$ and 9 , respectively. The state equations $(n=3)$ for the angle of attack $(\alpha)$, pitch rate $(q)$ and the pitch angle $(\theta)$ are

$$
\begin{aligned}
\dot{\alpha}= & -\frac{\bar{q} S}{m V} C_{L}+q+\frac{g}{V}\left(\cos \left(\phi_{m}\right) \cos \left(\alpha_{m}\right) \cos (\theta)+\sin \left(\alpha_{m}\right) \sin (\theta)\right) \\
& -\beta_{m}\left(p_{m} \cos \left(\alpha_{m}\right)+r_{m} \sin \left(\alpha_{m}\right)\right) \\
\dot{q}= & \frac{\bar{q} S \bar{c}}{I y y}\left(C_{m_{\alpha}} \alpha+C_{m_{q}} \frac{\bar{c}}{2 V} q+C_{m_{\delta_{e}}} \delta_{e}+C_{m_{0}}\right)+\frac{I z z-I x x}{I y y} r_{m} p_{m} \\
\dot{\theta}= & q \cos \left(\phi_{m}\right)-r_{m} \sin \left(\phi_{m}\right)+\theta_{0} .
\end{aligned}
$$

The measurement equations $(m=5)$ are

$$
\begin{aligned}
& \alpha_{m}=\alpha-K_{\alpha} x_{\alpha} \frac{q}{V} ; \quad q_{m}=q ; \quad \theta_{m}=\theta ; \\
& a_{n_{m}}=\frac{\bar{q} S}{m g} C_{N}+\frac{x_{a_{n}}}{g} \dot{q} ; a_{x_{m}}=-\frac{\bar{q} S}{m g} C_{A}+\frac{z_{a_{x}}}{g} \dot{q}
\end{aligned}
$$

where 
Table 5. Real flight test data case-3 results $\left(\Theta, \sigma_{\Theta}\right)$.

\begin{tabular}{|c|c|c|c|c|c|}
\hline$\Theta$ & RRR & NASA & Gemson & MT & MS \\
\hline$C_{Y_{\beta}}$ & $\begin{array}{l}-0.4579 \\
(0.0043)\end{array}$ & $\begin{array}{c}-0.4792 \\
(0.01711)\end{array}$ & $\begin{array}{l}-0.4761 \\
(0.0043)\end{array}$ & $\begin{array}{l}-0.4541 \\
(0.0053)\end{array}$ & $\begin{array}{l}-0.4642 \\
(0.0049)\end{array}$ \\
\hline$C_{Y_{\delta_{r}}}$ & $\begin{array}{c}0.1040 \\
(0.0067)\end{array}$ & $\begin{array}{c}0.0887 \\
(0.01955)\end{array}$ & $\begin{array}{c}0.0981 \\
(0.0065)\end{array}$ & $\begin{array}{c}0.0741 \\
(0.0065)\end{array}$ & $\begin{array}{c}0.0797 \\
(0.0057)\end{array}$ \\
\hline$\beta_{0}$ & $\begin{array}{l}-0.0143 \\
(0.0048)\end{array}$ & $\begin{array}{l}-0.10116 \\
(0.00294)\end{array}$ & $\begin{array}{l}-0.0124 \\
(0.0021)\end{array}$ & $\begin{array}{l}-0.0107 \\
(0.0034)\end{array}$ & $\begin{array}{l}-0.0109 \\
(0.0009)\end{array}$ \\
\hline$C_{L_{\beta}}$ & $\begin{array}{l}-0.0168 \\
(0.0005)\end{array}$ & $\begin{array}{c}-0.0205 \\
(0.00107)\end{array}$ & $\begin{array}{l}-0.0182 \\
(0.0011)\end{array}$ & $\begin{array}{l}-0.0170 \\
(0.0004)\end{array}$ & $\begin{array}{l}-0.0177 \\
(0.0003)\end{array}$ \\
\hline$C_{L_{p}}$ & $\begin{array}{l}-0.3100 \\
(0.0028)\end{array}$ & $\begin{array}{c}-0.36 \\
(0.00713)\end{array}$ & $\begin{array}{l}-0.3585 \\
(0.0048)\end{array}$ & $\begin{array}{l}-0.3112 \\
(0.0027)\end{array}$ & $\begin{array}{l}-0.3080 \\
(0.0022)\end{array}$ \\
\hline$C_{L_{r}}$ & $\begin{array}{c}0.0740 \\
(0.0030)\end{array}$ & $\begin{array}{c}0.0697 \\
(0.005884)\end{array}$ & $\begin{array}{c}0.0731 \\
(0.0066)\end{array}$ & $\begin{array}{c}0.0733 \\
(0.0028)\end{array}$ & $\begin{array}{c}0.0757 \\
(0.0022)\end{array}$ \\
\hline$C_{L_{\delta_{a}}}$ & $\begin{array}{c}0.0557 \\
(0.0004)\end{array}$ & $\begin{array}{c}0.0612 \\
(0.001050)\end{array}$ & $\begin{array}{c}0.0622 \\
(0.0007)\end{array}$ & $\begin{array}{c}0.0557 \\
(0.0004)\end{array}$ & $\begin{array}{c}0.0546 \\
(0.0003)\end{array}$ \\
\hline$C_{L_{\delta_{r}}}$ & $\begin{array}{c}0.0072 \\
(0.0007)\end{array}$ & $\begin{array}{c}0.006 \\
(0.001252)\end{array}$ & $\begin{array}{c}0.0089 \\
(0.0031)\end{array}$ & $\begin{array}{c}0.0073 \\
(0.0007)\end{array}$ & $\begin{array}{c}0.0082 \\
(0.0005)\end{array}$ \\
\hline$C_{L_{0}}$ & $\begin{array}{l}-0.0020 \\
(0.0001)\end{array}$ & $\begin{array}{c}-0.002 \\
(0.0001467)\end{array}$ & $\begin{array}{l}-0.0023 \\
(0.0003)\end{array}$ & $\begin{array}{l}-0.0020 \\
(0.0001)\end{array}$ & $\begin{array}{l}-0.0021 \\
(0.0001)\end{array}$ \\
\hline$\phi_{0}$ & $\begin{array}{c}0.0018 \\
(0.0027)\end{array}$ & $\begin{array}{c}0.1506 \\
(0.07034)\end{array}$ & $\begin{array}{c}0.0023 \\
(0.0011)\end{array}$ & $\begin{array}{c}0.0019 \\
(0.0012)\end{array}$ & $\begin{array}{c}0.0019 \\
(0.0013)\end{array}$ \\
\hline$C_{N_{\beta}}$ & $\begin{array}{c}0.0656 \\
(0.0005)\end{array}$ & $\begin{array}{c}0.0705 \\
(0.000478)\end{array}$ & $\begin{array}{c}0.0703 \\
(0.0009)\end{array}$ & $\begin{array}{c}0.0657 \\
(0.0004)\end{array}$ & $\begin{array}{c}0.0662 \\
(0.0004)\end{array}$ \\
\hline$C_{N_{p}}$ & $\begin{array}{l}-0.0429 \\
(0.0031)\end{array}$ & $\begin{array}{c}-0.046 \\
(0.004006)\end{array}$ & $\begin{array}{l}-0.0557 \\
(0.0039)\end{array}$ & $\begin{array}{l}-0.0473 \\
(0.0023)\end{array}$ & $\begin{array}{l}-0.0596 \\
(0.0021)\end{array}$ \\
\hline$C_{N_{r}}$ & $\begin{array}{l}-0.0880 \\
(0.0033)\end{array}$ & $\begin{array}{c}-0.1062 \\
(0.003562)\end{array}$ & $\begin{array}{l}-0.0576 \\
(0.0045)\end{array}$ & $\begin{array}{l}-0.0854 \\
(0.0023)\end{array}$ & $\begin{array}{l}-0.1021 \\
(0.0010)\end{array}$ \\
\hline$C_{N_{\delta_{a}}}$ & $\begin{array}{c}0.0004 \\
(0.0005)\end{array}$ & $\begin{array}{c}0.0006 \\
(0.0005924)\end{array}$ & $\begin{array}{c}0.0033 \\
(0.0006)\end{array}$ & $\begin{array}{c}0.0010 \\
(0.0003)\end{array}$ & $\begin{array}{c}0.0030 \\
(0.0003)\end{array}$ \\
\hline$C_{N_{\delta_{r}}}$ & $\begin{array}{l}-0.0478 \\
(0.0008)\end{array}$ & $\begin{array}{c}-0.0513 \\
(0.0009139)\end{array}$ & $\begin{array}{l}-0.048 \\
(0.0013)\end{array}$ & $\begin{array}{l}-0.0476 \\
(0.0006)\end{array}$ & $\begin{array}{l}-0.0502 \\
(0.0003)\end{array}$ \\
\hline$C_{N_{0}}$ & $\begin{array}{c}0.0067 \\
(0.0001)\end{array}$ & $\begin{array}{c}0.0072 \\
(0.0001181)\end{array}$ & $\begin{array}{c}0.0068 \\
(0.0002)\end{array}$ & $\begin{array}{c}0.0067 \\
(0.0001)\end{array}$ & $\begin{array}{c}0.0069 \\
(0.00003)\end{array}$ \\
\hline$C_{Y_{0}}$ & $\begin{array}{l}-0.0259 \\
(0.0008)\end{array}$ & $\begin{array}{c}-0.0242 \\
(0.002307)\end{array}$ & $\begin{array}{l}-0.0251 \\
(0.0007)\end{array}$ & $\begin{array}{l}-0.0221 \\
(0.0008)\end{array}$ & $\begin{array}{l}-0.0228 \\
(0.0007)\end{array}$ \\
\hline$C_{Y_{p}}$ & $\begin{array}{l}-0.2828 \\
(0.0327)\end{array}$ & & & $\begin{array}{c}0.0821 \\
(0.2941)\end{array}$ & $\begin{array}{c}0.5223 \\
(0.0710)\end{array}$ \\
\hline$C_{Y_{r}}$ & $\begin{array}{c}0.2224 \\
(0.0281)\end{array}$ & & & $\begin{array}{l}-1.2336 \\
(0.4470)\end{array}$ & $\begin{array}{l}-0.8452 \\
(0.1355)\end{array}$ \\
\hline$C_{Y_{\delta_{a}}}$ & $\begin{array}{c}0.0384 \\
(0.0047)\end{array}$ & & & $\begin{array}{c}0.0011 \\
(0.0026)\end{array}$ & $\begin{array}{l}-0.0017 \\
(0.0024)\end{array}$ \\
\hline
\end{tabular}

$$
\begin{aligned}
C_{L} & =C_{N} \cos (\alpha)-C_{A} \sin (\alpha)+C_{L_{0}} \\
C_{N} & =C_{N_{\alpha}} \alpha+C_{N_{\delta_{e}}} \delta_{e}+C_{N_{0}} \\
C_{A} & =C_{A_{\alpha}} \alpha+C_{A_{\alpha^{2}}} \alpha^{2}+C_{A_{\delta_{e}}} \delta_{e}+C_{A_{0}} .
\end{aligned}
$$

The unknown parameter set $(p=13)$ is $\Theta=\left(C_{N_{\alpha}}, C_{N_{\delta_{e}}}, C_{L_{0}}\right.$, $\left.C_{m_{\alpha}}, C_{m_{q}}, C_{m_{\delta_{e}}}, C_{m_{0}}, \theta_{0}, C_{N_{0}}, C_{A_{\alpha}}, C_{A_{\alpha^{2}}}, C_{A_{\delta_{e}}}, C_{A_{0}}\right)^{\mathrm{T}}$. The ones with suffix ' $\delta_{e}$ ' are the control derivatives, the ones with suffix zero are the biases and all others are aerodynamic derivatives. The initial states are taken as initial measurement and the initial parameter values are taken as $(4,0.24,0.17,-0.48,-17$, $-0.9,-0.05,-0.02,0.175,-0.3,0.03,-0.083,-0.015)^{\mathrm{T}}$.

Other constant values used for case-1 are as follows:

\begin{tabular}{cccccc}
\hline $\bar{c}=$ & $S=$ & $m=$ & $I x x=$ & $I y y=$ & $I z z=$ \\
5.58 & 184 & 172.667 & 4142.9 & 3922.4 & 7642.5 \\
$g=$ & $V=$ & $\bar{q}=$ & $K_{\alpha} x_{\alpha}=$ & $x_{a_{n}}=$ & $z_{a_{x}}=$ \\
32.2 & 403.1 & 83.08 & -0.0279 & 0.101 & -1.17 \\
\hline
\end{tabular}

\subsection{Remarks on the real data case-1 results}

Figures 1-5 show the inputs used in the state equations. The variations of the absolute value of the estimated initial parameters and their $\mathbf{P}_{\mathbf{0}}$ with iterations are shown in figure 6 and similarly in figure 7 for $\mathbf{Q}$ and $\mathbf{R}$ and in figure 8 for the cost functions $\mathbf{J 1 - J 8}$. Figures 9 and 10 compare the measurements with (i) the state dynamics based on the estimated parameters, (ii) the state after measurement update and (iii) the smoothed state.

Another feature of recursive parameter estimation is that it can vary through time instants and point to two distinct values as reflected in the estimation of $C_{N_{\alpha}}$ in figure 11. This feature of tracking time-varying parameters by the EKF brings in clearly another advantage of sequential processing instead of batch processing of the data by a least squares (LS) procedure. If LS had been used then for the parameter $\left(C_{N_{\alpha}}\right)$ only an average value would have been

\begin{tabular}{|c|c|c|c|c|c|c|c|c|}
\hline $\begin{array}{l}\mathbf{R} \times 10^{-6} \\
(\text { Ref })\end{array}$ & $\mathbf{Q} \times 10^{-6}($ Ref $)$ & $\begin{array}{c}\text { J1-J8 } \\
\text { (Ref) }\end{array}$ & $\begin{array}{c}\mathbf{R}(\mathrm{MT}) \\
\times 10^{-6}\end{array}$ & $\begin{array}{c}\mathbf{Q}(\mathrm{MT}) \\
\times 10^{-6}\end{array}$ & $\begin{array}{c}\text { J1-J8 } \\
\text { (MT) }\end{array}$ & $\begin{array}{c}\mathbf{R}(\mathrm{MS}) \\
\times 10^{-6}\end{array}$ & $\begin{array}{l}\mathbf{Q}(\mathrm{MS}) \\
\times 10^{-6}\end{array}$ & $\begin{array}{c}\text { J1-J8 } \\
(\mathrm{MS})\end{array}$ \\
\hline & & 4.7650 & & & 4.3450 & & & 4.8127 \\
\hline 0.0871 & & 4.8321 & & & 4.3888 & & & 4.8200 \\
\hline 0.0623 & 4.2163 & 3.5272 & 2.83 & & 3.1039 & 13.03 & 0.0005 & 4.5173 \\
\hline 0.2255 & 5.1340 & 0.0004 & 18.86 & 2.0481 & 0.0003 & 88.07 & 0.0007 & 0.0003 \\
\hline 0.0200 & 4.9426 & -55.0111 & 3.88 & 3.7876 & -51.3490 & 4.5 & 1.0975 & -47.2441 \\
\hline \multirow[t]{3}{*}{43.8064} & 1.4324 & 3.9673 & 4.09 & 1.0057 & 9.3006 & 36.36 & 0.0016 & 7.5931 \\
\hline & & 3.9669 & 73.6 & 0.5502 & 9.3005 & 60.13 & & 7.5896 \\
\hline & & 3.8171 & & & 3.5105 & & & 3.9681 \\
\hline
\end{tabular}
obtained.

Table 6. Real flight test data case-3 results ${ }^{\mathrm{a}}(\mathbf{R}, \mathbf{Q}, \mathbf{J})$.

${ }^{a}$ Cost functions are not close to their expected values in MT and MS methods 


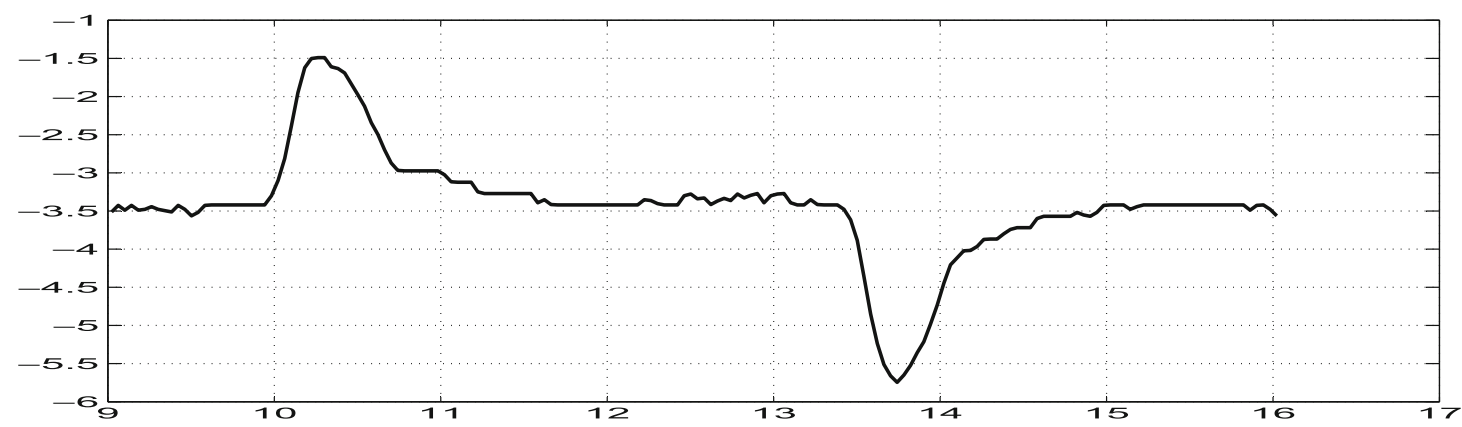

Figure 1. Control input ( $\delta_{e}$ in deg) versus time (s).

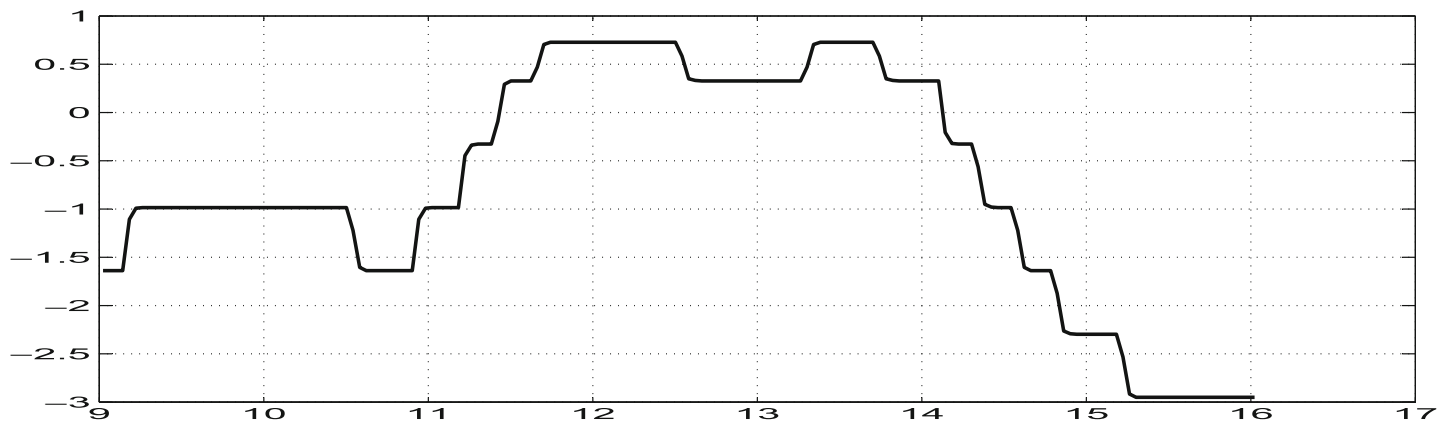

Figure 2. Input roll angle( $\phi_{m}$ in deg) versus time (s).

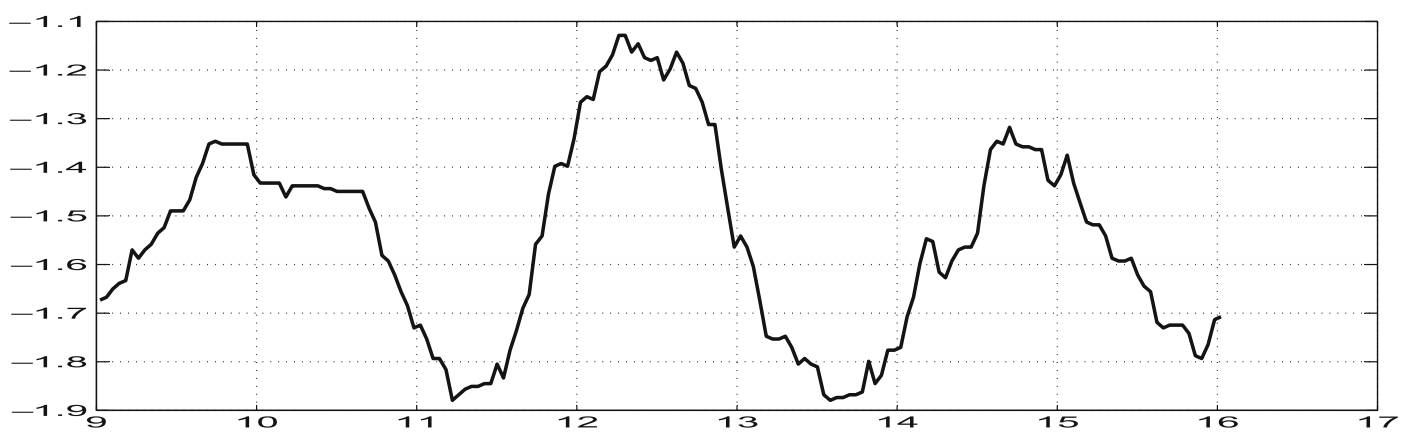

Figure 3. Input sideslip ( $\beta_{m}$ in deg) versus time (s).

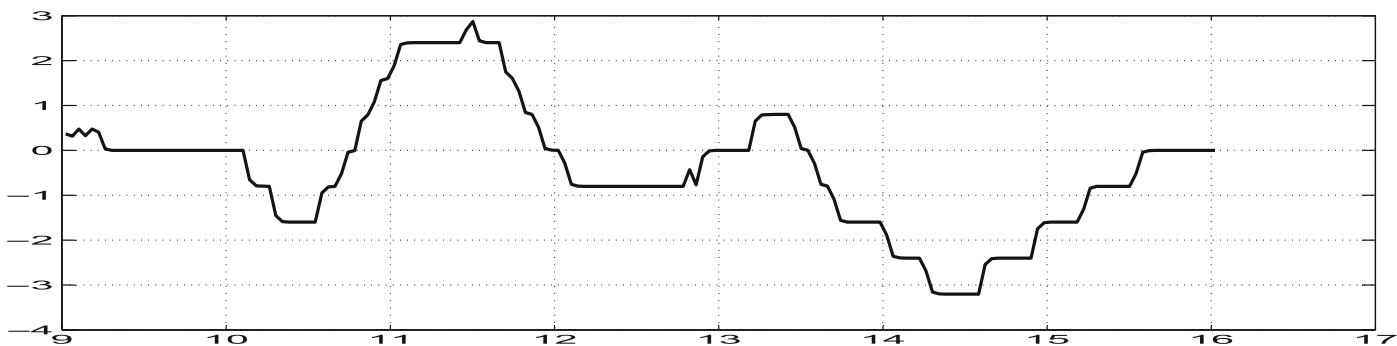

Figure 4. Input roll rate ( $p_{m}$ in $\left.\mathrm{deg} / \mathrm{s}\right)$ versus time (s). 


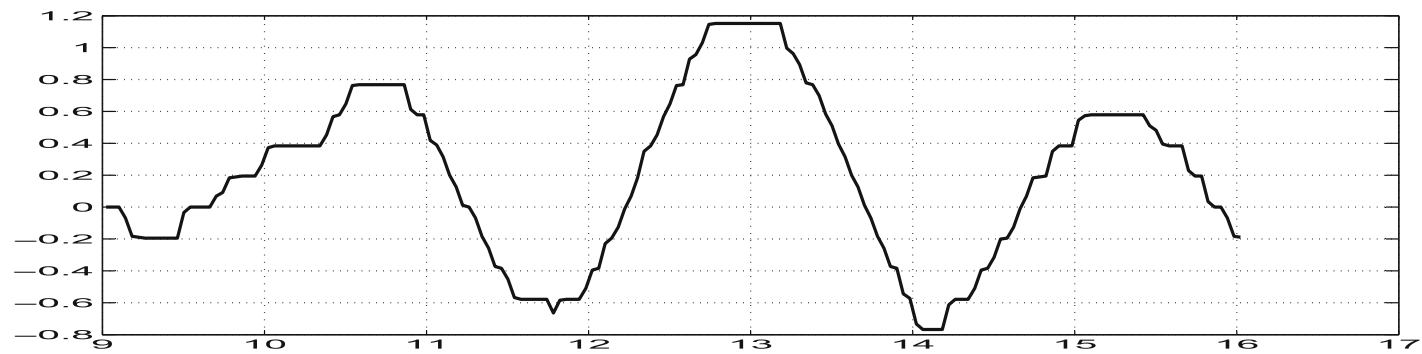

Figure 5. Input yaw rate $\left(r_{m}\right.$ in $\left.\mathrm{deg} / \mathrm{s}\right)$ versus time (s).

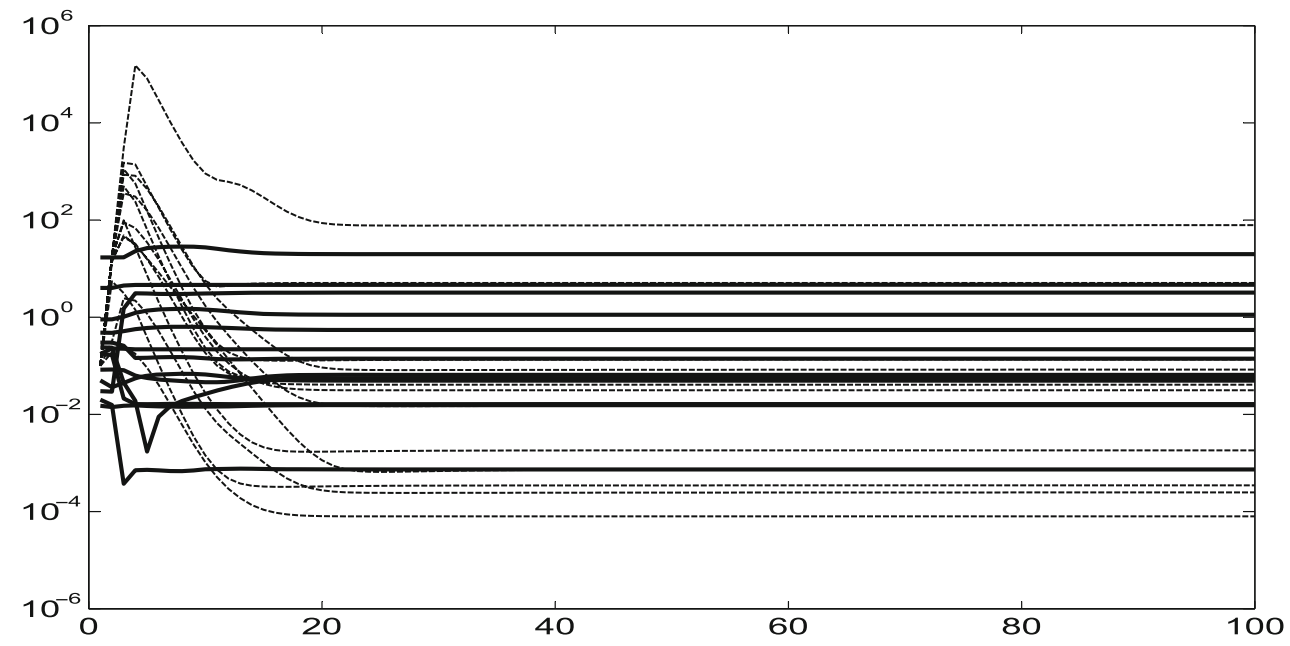

Figure 6. Variation of initial parameters $\Theta_{0}$ (continuous) and their $\mathbf{P}_{\mathbf{0}}$ (dashed) with iterations.

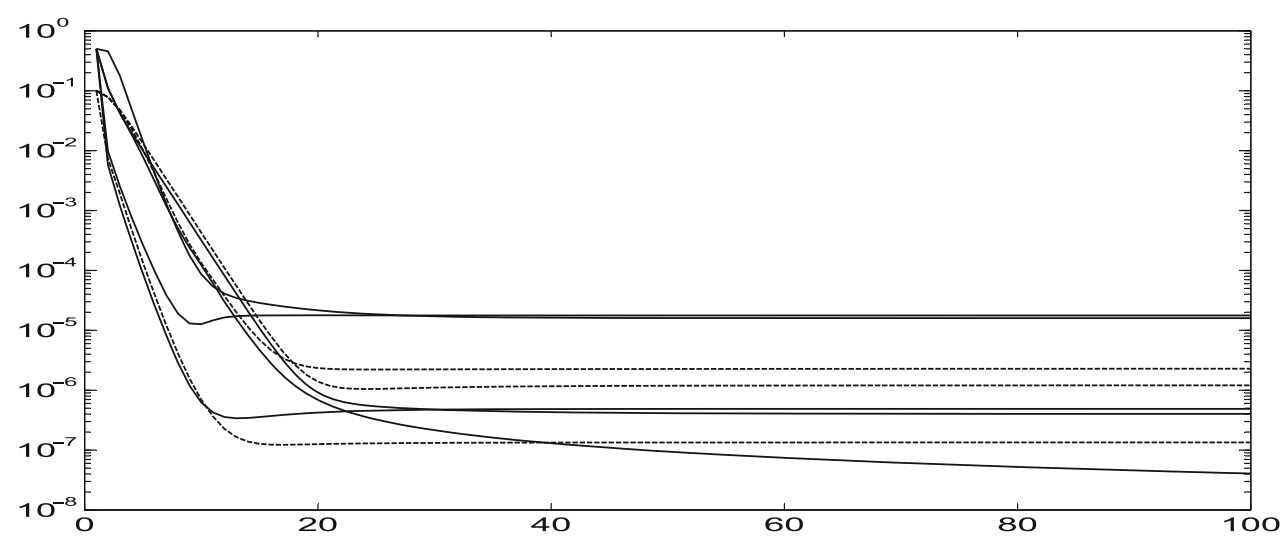

Figure 7. Variation of $\mathbf{Q}$ (dashed) and $\mathbf{R}$ (continuous) with iterations. 


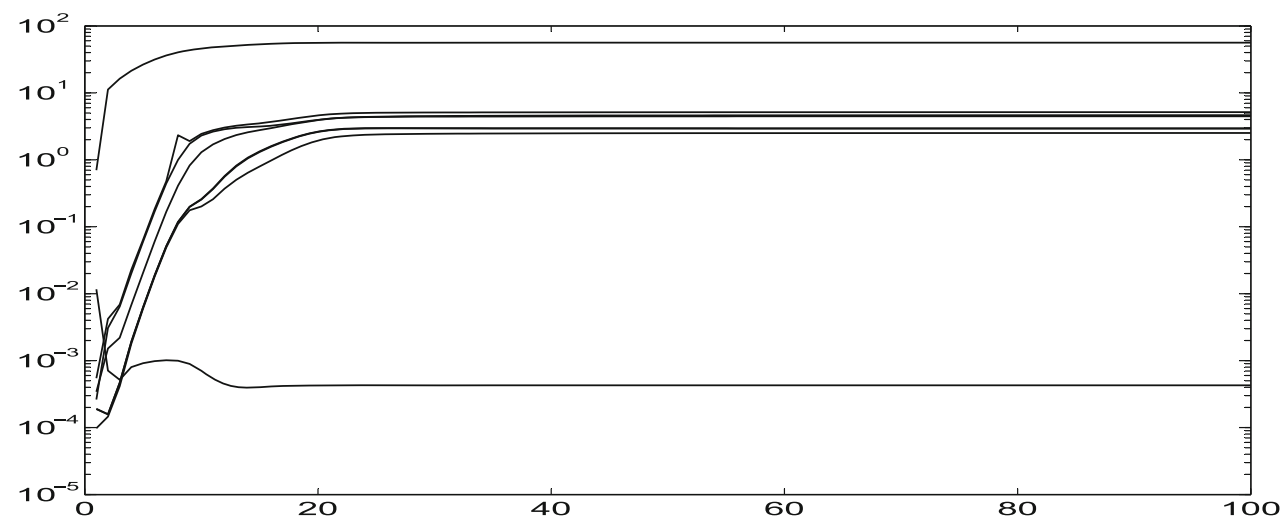

Figure 8. Variation of different costs (J1-J8) with iterations.

(a)

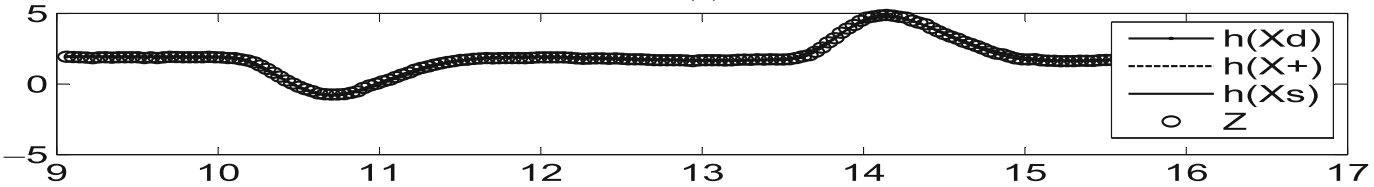

(b)

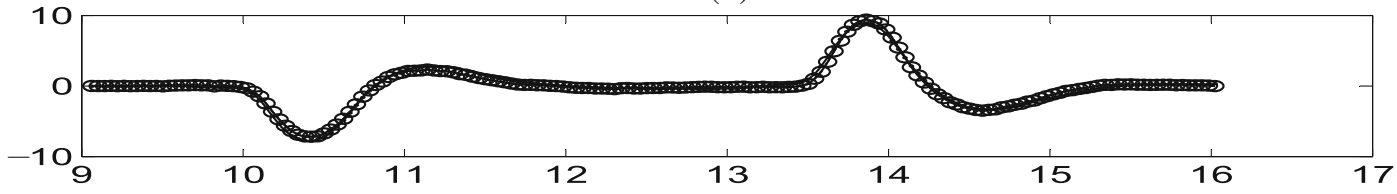

(c)

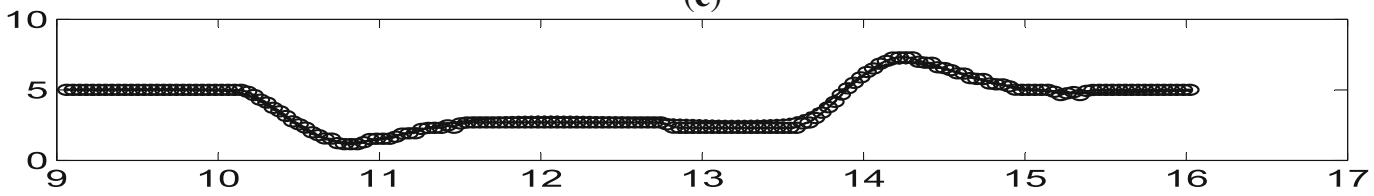

Figure 9. Comparison of the predicted dynamics, posterior, smoothed and measurement ((a) angle of attack (deg), (b) pitch rate (deg/s) and (c) pitch angle (deg)) versus time.

(a)

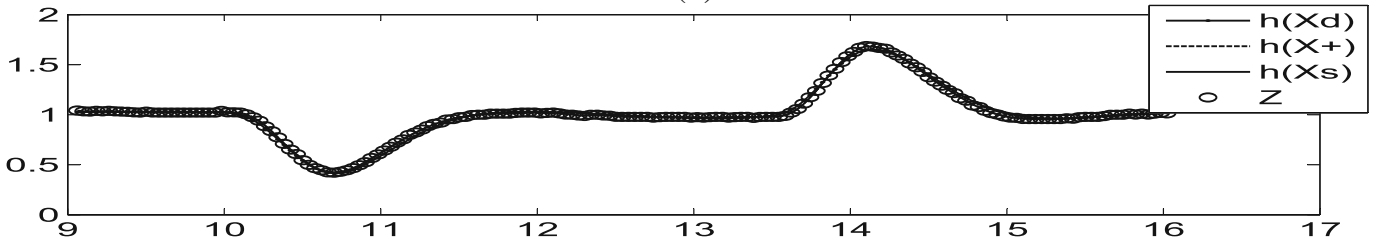

(b)

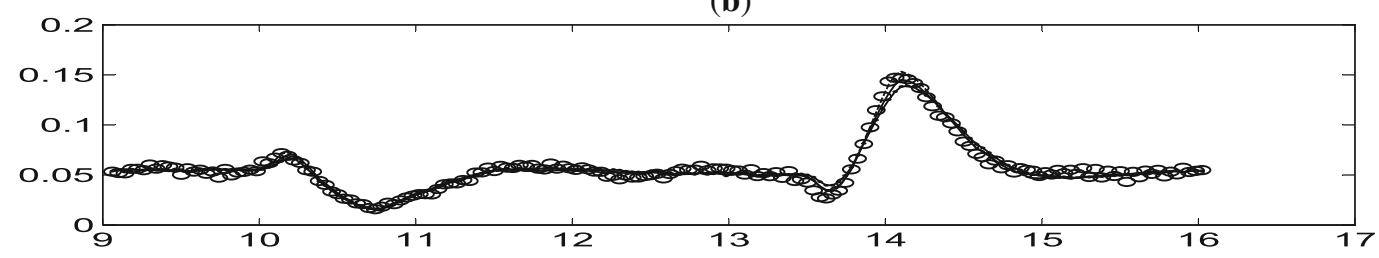

Figure 10. Comparison of the predicted dynamics, posterior, smoothed and measurement in $g$, (a) normal acceleration and (b) axial acceleration versus time. 


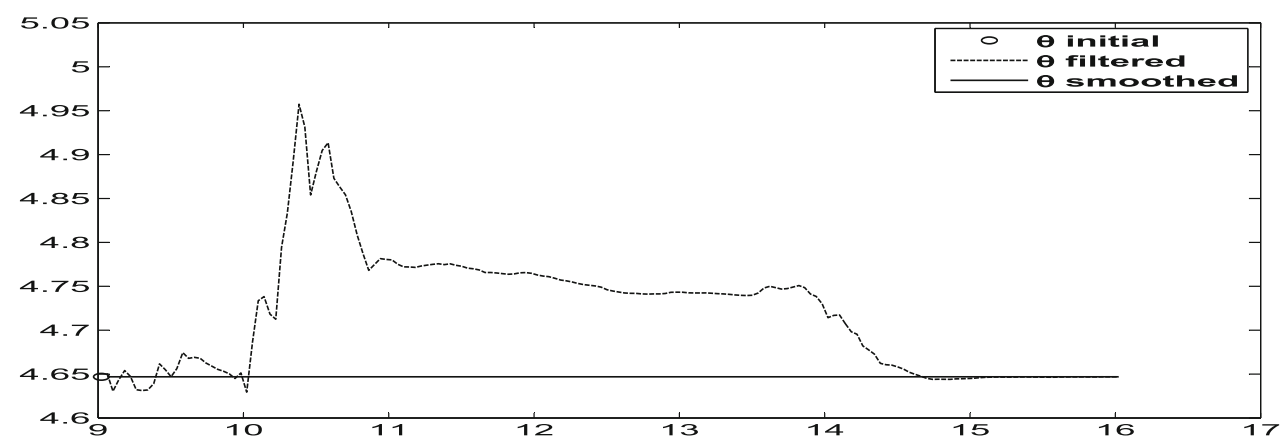

Figure 11. Variation of the parameter estimate $\left(C_{N_{\alpha}}\right)$ through time instants.

\begin{tabular}{|c|c|c|c|c|c|c|c|c|c|c|c|c|c|}
\hline$\Theta$ & $C_{N_{\alpha}}$ & $C_{N_{\delta_{e}}}$ & $C_{L_{0}}$ & $C_{m_{\alpha}}$ & $C_{m_{q}}$ & $C_{m_{\delta_{e}}}$ & $C_{m_{0}}$ & $\theta_{0}$ & $C_{N_{0}}$ & $C_{A_{\alpha}}$ & $C_{A_{\alpha^{2}}}$ & $C_{A_{\delta_{e}}}$ & $C_{A_{0}}$ \\
\hline$C_{N_{\alpha}}$ & 100 & 62 & 0 & -18 & 0 & -7 & -3 & 0 & 32 & -1 & -10 & -10 & -8 \\
\hline$C_{N_{\delta_{e}}}$ & 62 & 100 & 0 & -10 & 1 & -11 & -10 & 0 & 93 & -4 & -2 & -16 & -15 \\
\hline$C_{L_{0}}$ & 0 & 0 & 100 & 0 & 0 & 0 & 0 & 0 & 0 & 0 & 0 & 0 & 0 \\
\hline$C_{m_{\alpha}}$ & -18 & -10 & 0 & 100 & 18 & 51 & 31 & 0 & -5 & -15 & 1 & -15 & -7 \\
\hline$C_{m_{q}}$ & 0 & 1 & 0 & 18 & 100 & 76 & 79 & 0 & 1 & 6 & -3 & 5 & 2 \\
\hline$C_{m_{\delta_{e}}}$ & -7 & -11 & 0 & 51 & 76 & 100 & 97 & 0 & -10 & -1 & -2 & -14 & -14 \\
\hline$C_{m_{0}}$ & -3 & -10 & 0 & 31 & 79 & 97 & 100 & 0 & -11 & 2 & -3 & -11 & -15 \\
\hline$\theta_{0}$ & 0 & 0 & 0 & 0 & 0 & 0 & 0 & 100 & 0 & 0 & 0 & 0 & 0 \\
\hline$C_{N_{0}}$ & 32 & 93 & 0 & -5 & 1 & -10 & -11 & 0 & 100 & -5 & 2 & -15 & -15 \\
\hline$C_{A_{\alpha}}$ & -1 & -4 & 0 & -15 & 6 & -1 & 2 & 0 & -5 & 100 & -83 & 42 & 6 \\
\hline$C_{A_{\alpha^{2}}}$ & -10 & -2 & 0 & 1 & -3 & -2 & -3 & 0 & 2 & -83 & 100 & -7 & 16 \\
\hline$C_{A_{\delta_{e}}}^{\alpha^{2}}$ & -10 & -16 & 0 & -15 & 5 & -14 & -11 & 0 & -15 & 42 & -7 & 100 & 91 \\
\hline$C_{A_{0}}$ & -8 & -15 & 0 & -7 & 2 & -14 & -15 & 0 & -15 & 6 & 16 & 91 & 100 \\
\hline
\end{tabular}

Table 1 provides a comparison of the parameter estimates along with their CRBs (in parenthesis) for all the real data studied by different approaches such as MT and MS with scaled up $\mathbf{P}_{\mathbf{0}}$. Since the NASA results are obtained with $\mathbf{Q}=0$ only a comparison with other approaches is valid. Generally the CRBs from the RRR is lower than from other approaches and at times their lower CRBs is only fortuitous. The rounded $100 \mathrm{C}$ matrix of the parameter estimates is

Based on the correlation coefficient matrix from RRR for this case with 13 unknown parameters the weakest can be inferred as $\theta_{0}$ and $C_{L_{0}}$, which are almost uncorrelated with all other parameters. Hence their estimates and uncertainty can vary widely among the approaches. Next it is possible to group the parameters as $\left(C_{A_{0}}, C_{A_{\delta_{e}}}\right),\left(C_{A_{\alpha}}, C_{A_{\alpha^{2}}}\right),\left(C_{M_{0}}, C_{M_{\delta_{e}}}\right)$, $\left(C_{M_{\alpha}}, C_{M_{q}}\right),\left(C_{N_{0}}, C_{N_{\delta_{e}}}\right)$ and $\left(C_{N_{\alpha}}, C_{N_{\delta_{e}}}\right)$. The estimation of the aerodynamic parameters depends on two factors, namely their representation and the excitation. The first group is highly correlated since over a range of excitation by the elevator represented by $\delta_{e}$ it could have been difficult to discriminate between the two as seen by the high correlation between them. A similar behaviour is seen in the second, third, fifth and sixth groups, the last being not that highly correlated. Though the fourth group represents the pitching moment the excitation by $\alpha$ and $q$ helps discriminate them as indicated by the low correlation between them. It is this feature that should be kept in mind by a designer using the above estimates for further use.

\section{Analysis of real flight test case-2}

The data set is obtained from NASA TP 1690 [3] by employing a peculiar manoeuvre where elevator control input $\left(\delta_{e}\right.$ in $\left.\mathrm{deg}\right)$ shown in figure 12 is imparted when the aircraft $(\mathrm{T} 37 \mathrm{~B})$ is rolling through a full rotation about its $x$-axis during aileron roll. Similar to the earlier case, the coupling between the longitudinal and lateral motion is replaced by their measured values, which includes roll angle $\left(\phi_{m}\right)$, sideslip $\left(\beta_{m}\right)$, velocity $\left(V_{m}\right)$, roll rate $\left(p_{m}\right)$, yaw rate $\left(r_{m}\right)$ and the angle of attack $\left(\alpha_{m}\right)$ as shown in figures $13,14,15,16,17$ and 21 , respectively. The state equations $(n=3)$ for the angle of attack $(\alpha)$, pitch rate $(q)$ and the pitch angle $(\theta)$, respectively, are

$$
\begin{aligned}
\dot{\alpha}= & -\frac{\bar{q} S}{m V_{m} \cos \left(\beta_{m}\right)}\left(C_{L_{\alpha}} \alpha+C_{L_{\delta_{e}}} \delta_{e}+C_{L_{0}}\right)+q \\
& +\frac{g}{V_{m} \cos \left(\beta_{m}\right)}\left(\cos \left(\phi_{m}\right) \cos \left(\alpha_{m}\right) \cos (\theta)\right. \\
& \left.+\sin \left(\alpha_{m}\right) \sin (\theta)\right)-\tan \left(\beta_{m}\right)\left(p_{m} \cos \left(\alpha_{m}\right)+r_{m} \sin \left(\alpha_{m}\right)\right) \\
\dot{q}= & \frac{\bar{q} S \bar{c}}{I y y}\left(C_{m_{\alpha}} \alpha+C_{m_{q}} \frac{\bar{c}}{2 V} q+C_{m_{\dot{\alpha}}} \frac{\bar{c}}{2 V} \dot{\alpha}+C_{m_{\delta_{e}}} \delta_{e}+C_{m_{0}}\right) \\
& +\frac{I z z-I x x}{I y y} r_{m} p_{m} \\
\dot{\theta}= & q \cos \left(\phi_{m}\right)-r_{m} \sin \left(\phi_{m}\right)+\theta_{0} .
\end{aligned}
$$




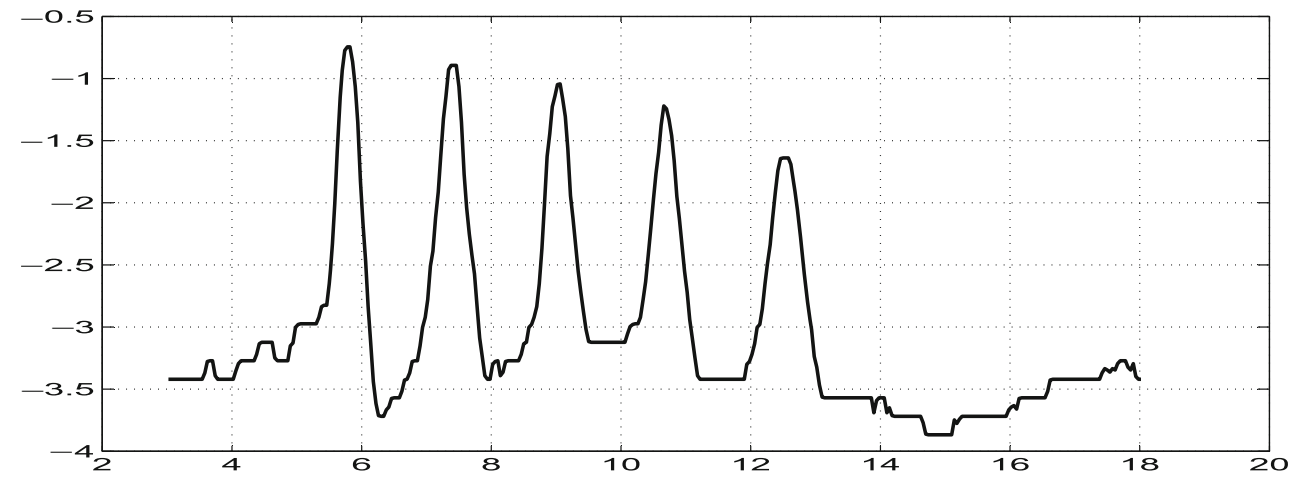

Figure 12. Control input ( $\delta_{e}$ in $\left.\mathrm{deg}\right)$ versus time (s).

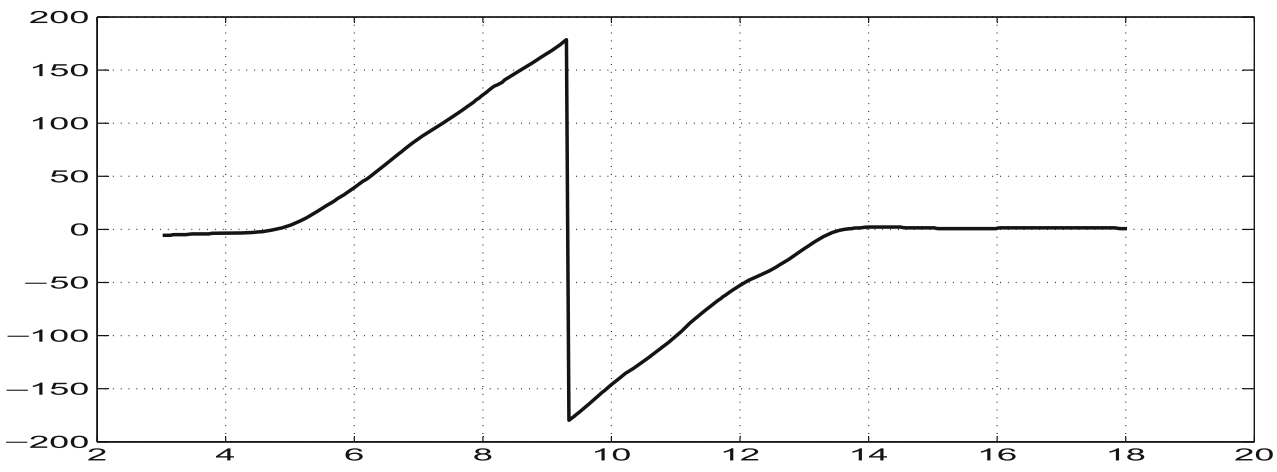

Figure 13. Input roll angle ( $\phi_{m}$ in deg) versus time (s).

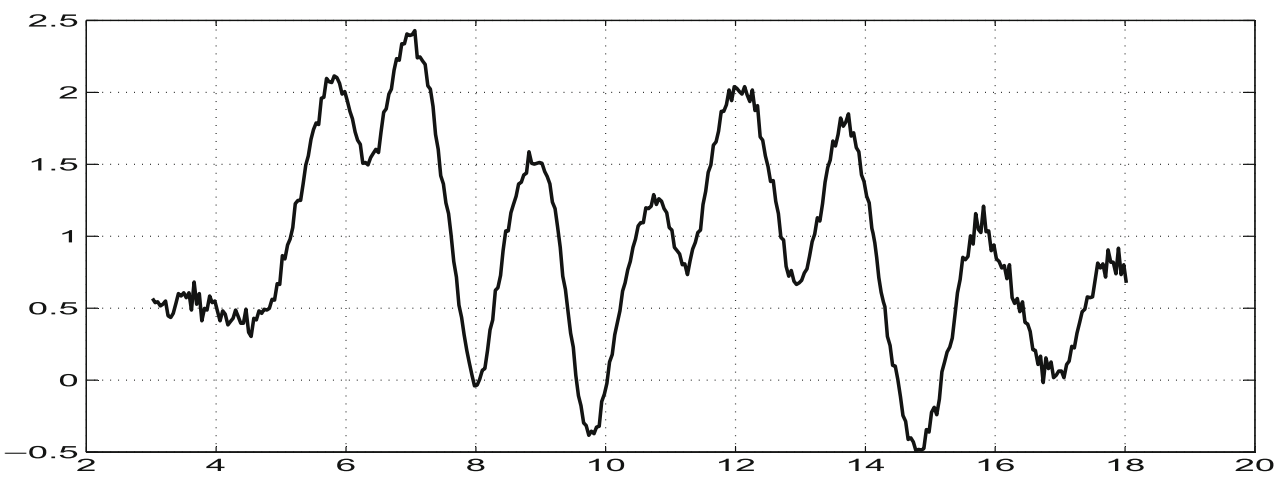

Figure 14. Input sideslip angle $\left(\beta_{m}\right.$ in deg) versus time (s).

The measurement equations $(m=4)$ are given by

$$
\begin{aligned}
\alpha_{m} & =K_{\alpha} \alpha-K_{\alpha} x_{\alpha} \frac{q}{V} ; \quad q_{m}=q ; \quad \theta_{m}=\theta ; \\
a_{n_{m}} & =\frac{\bar{q} S}{m g}\left(C_{N_{\alpha}} \alpha+C_{N_{\delta_{e}}} \delta_{e}+C_{N_{0}}\right)+\frac{x_{a_{n}}}{g} \dot{q} .
\end{aligned}
$$

The unknown parameters $(p=10)$ are $\left(C_{L_{\alpha}}, C_{L_{\delta_{e}}}, C_{L_{0}}\right.$, $\left.C_{m_{\alpha}}, C_{m_{q}}, C_{m_{\dot{\alpha}}}, C_{m_{\delta_{e}}}, C_{m_{0}}, \theta_{0}, C_{N_{0}}\right)^{\mathrm{T}}$ with an approximation $C_{N_{\alpha}}=C_{L_{\alpha}}$ and $C_{N_{\delta_{e}}}=C_{L_{\delta_{e}}}$. The ones with suffix ' $\delta_{e}$ ' are the control derivatives, the ones with suffix zero are the biases and all others are aerodynamic derivatives. The initial states are taken as initial measurement and the initial parameter values are taken as $(4,0.15,0.2,-0.5,-11.5$, $-5,-1.38,-0.06,-0.01,0.2)^{\mathrm{T}}$.

Other constant values used for case-2 are as follows:

\begin{tabular}{ccccc}
\hline$S=184$ & $m=196$ & $I x x=$ & Iyy $=3953.2$ & $I z z=$ \\
& & 6892.7 & & 10416.4 \\
$g=32.2$ & $\bar{c}=5.58$ & $K_{\alpha} x_{\alpha}=$ & $x_{a_{n}}=0.101$ & $K_{\alpha}=1$ \\
& & -0.0279 & &
\end{tabular}




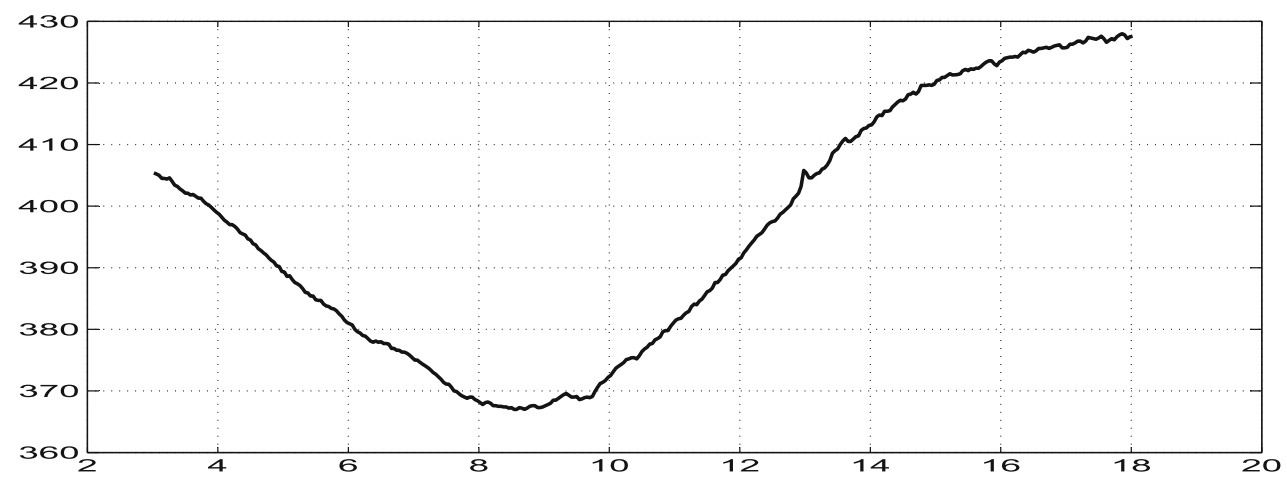

Figure 15. Input velocity $\left(V_{m}\right.$ in $\left.\mathrm{ft} / \mathrm{s}\right)$ versus time (s).

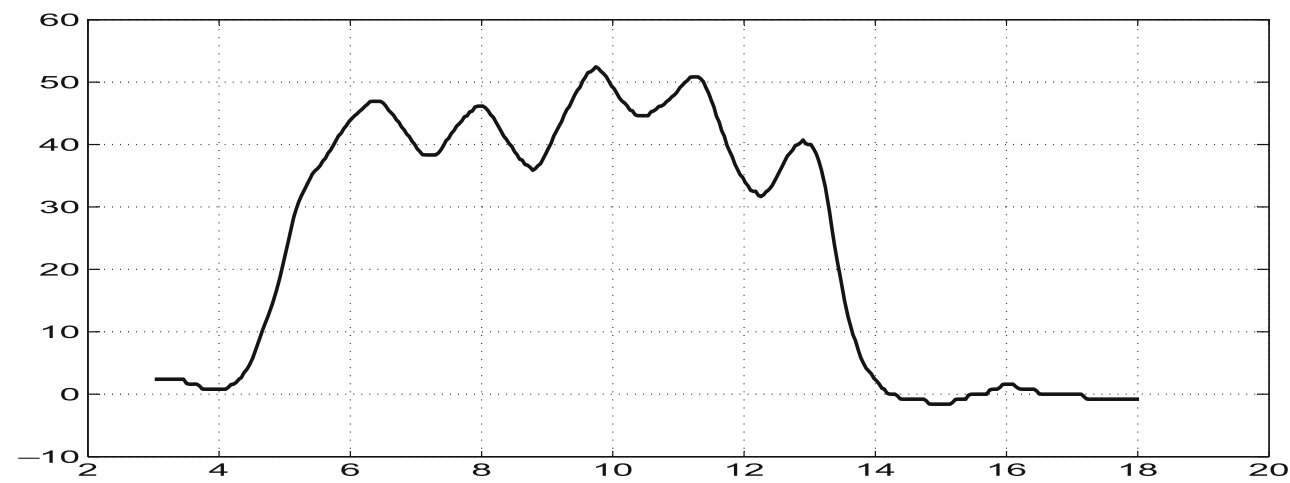

Figure 16. Input roll rate $\left(p_{m}\right.$ in $\left.\mathrm{deg} / \mathrm{s}\right)$ versus time (s).

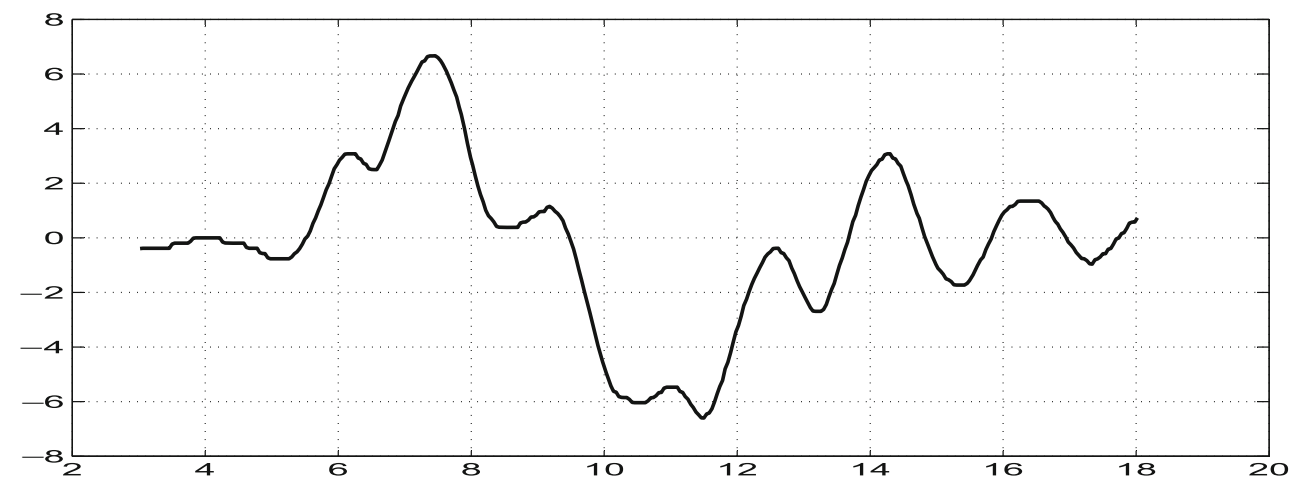

Figure 17. Input yaw rate $\left(r_{m}\right.$ in deg/s) versus time (s).

\subsection{Remarks on the real data case-2 results}

Figures 12-17 show the inputs used in the state equations. The variations of the absolute value of the estimated initial parameters and their $\mathbf{P}_{\mathbf{0}}$ with iterations are shown in figure 18 and similarly in figure 19 for $\mathbf{Q}$ and $\mathbf{R}$ and in figure 20 for the cost functions J1-J8. Figures 21 and 22 compare the measurements with the (i) the state dynamics based on the estimated parameters, (ii) the state after measurement update and (iii) the smoothed state.
Table 3 provides a comparison of the parameter estimates along with their CRBs (in parenthesis) for all the real data studied by different approaches. Since the NASA results are obtained with $\mathbf{Q}=0$ only a comparison with other approaches is valid. Generally the CRBs from the RRR is lower than from other approaches and at times their lower CRBs is only fortuitous. The rounded $100 C$ matrix of the parameter estimates is 


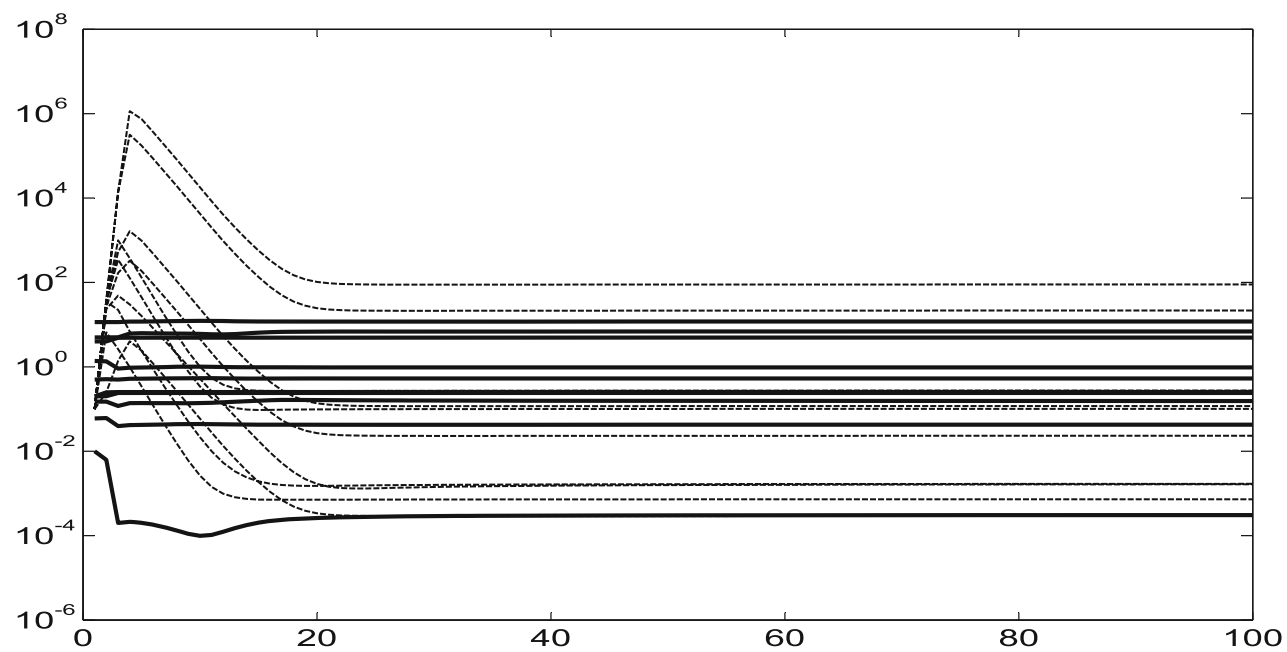

Figure 18. Variation of initial parameters $\Theta_{0}$ (continuous) and their $\mathbf{P}_{\mathbf{0}}$ (dashed) with iterations.

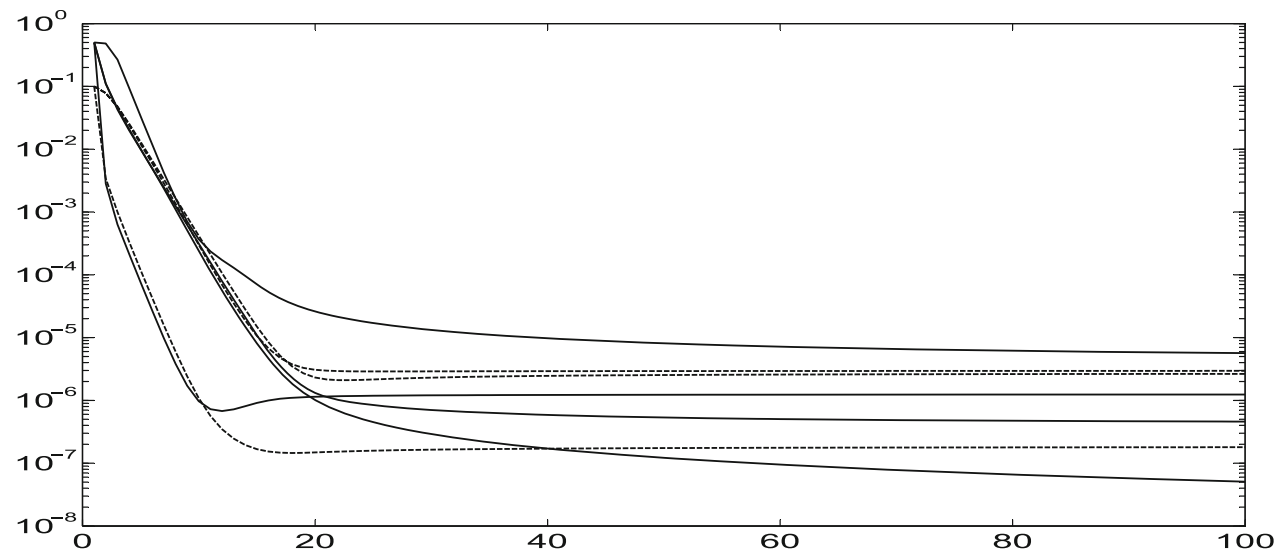

Figure 19. Variation of $\mathbf{Q}$ (dashed) and $\mathbf{R}$ (continuous) with iterations.

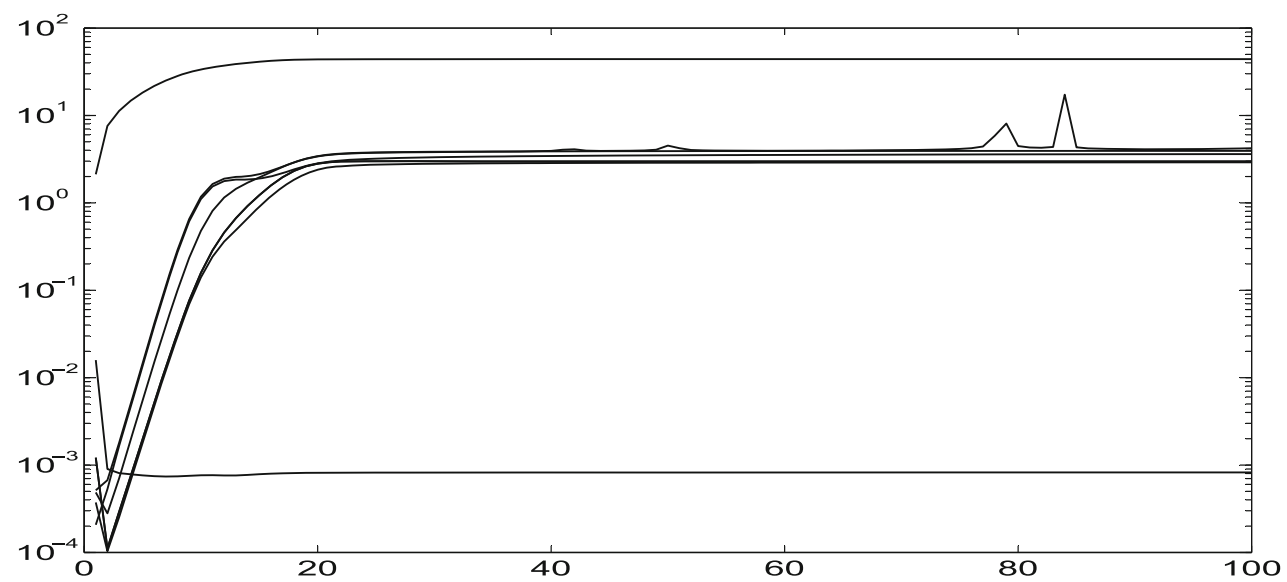

Figure 20. Variation of different costs $(\mathbf{J 1}-\mathbf{J 8})$ with iterations. 
(a)

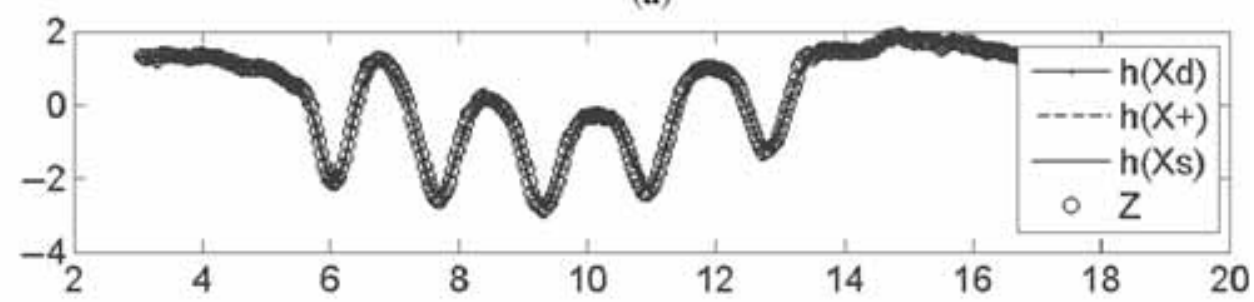

(b)

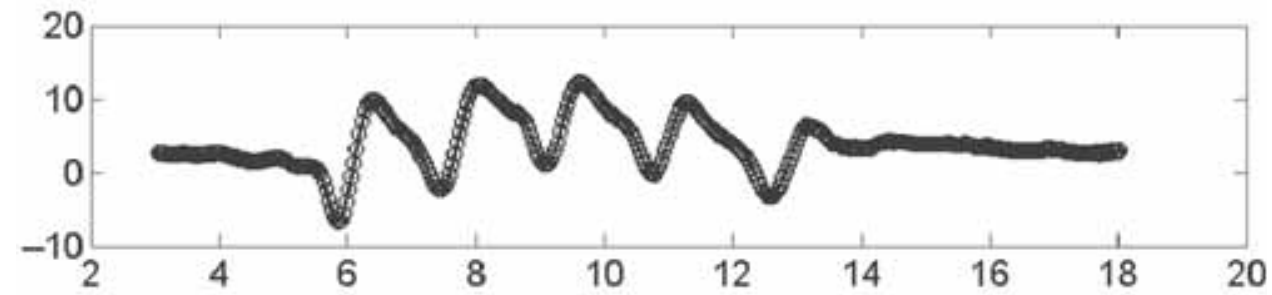

(c)

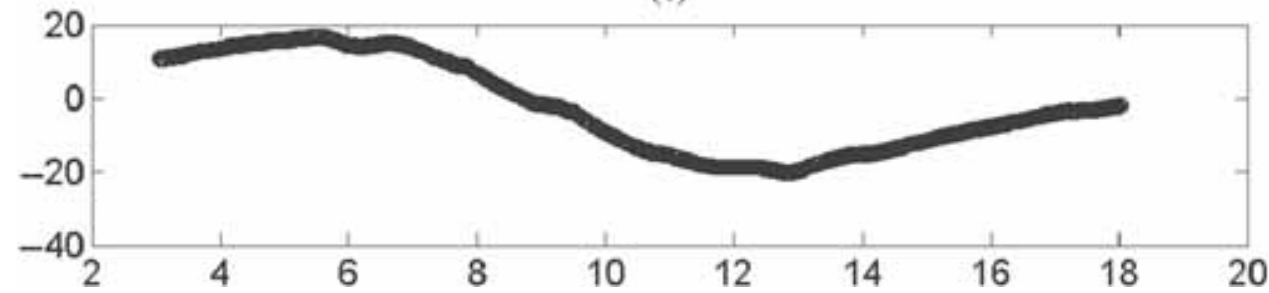

Figure 21. Comparison of the predicted dynamics, posterior, smoothed and the measurement, (a) angle of attack (deg), (b) pitch rate $(\mathrm{deg} / \mathrm{s})$ and $(\mathbf{c})$ pitch angle $(\mathrm{deg}))$ versus time.

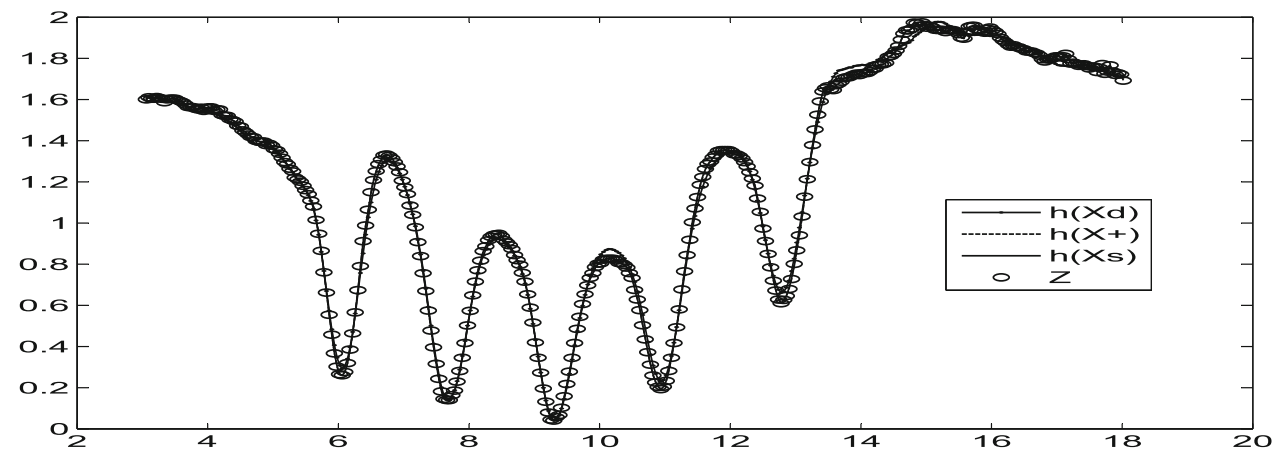

Figure 22. Comparison of the predicted dynamics, posterior, smoothed and the normal acceleration measurement in $g$ versus time.

\begin{tabular}{lcccccccccc}
$\Theta$ & $C_{L_{\alpha}}$ & $C_{L_{\delta_{e}}}$ & $C_{L_{0}}$ & $C_{m_{\alpha}}$ & $C_{m_{q}}$ & $C_{m_{\dot{\alpha}}}$ & $C_{m_{\delta_{e}}}$ & $C_{m_{0}}$ & $\theta_{0}$ & $C_{N_{0}}$ \\
\hline$C_{L_{\alpha}}$ & 100 & 67 & 41 & -19 & 1 & 1 & -8 & -8 & 0 & 62 \\
$C_{L_{\delta_{e}}}$ & 67 & 100 & 64 & -11 & 2 & 1 & -12 & -13 & 0 & 98 \\
$C_{L_{0}}$ & 41 & 64 & 100 & -4 & -2 & 5 & -5 & -7 & 0 & 65 \\
$C_{m_{\alpha}}$ & -19 & -11 & -4 & 100 & 25 & 70 & 91 & 88 & 0 & -10 \\
$C_{m_{q}}$ & 1 & 2 & -2 & 25 & 100 & -27 & 21 & 9 & 1 & 1 \\
$C_{m_{\dot{\alpha}}}$ & 1 & 1 & 5 & 70 & -27 & 100 & 80 & 84 & -1 & 2 \\
$C_{m_{\delta_{e}}}$ & -8 & -12 & -5 & 91 & 21 & 80 & 100 & 99 & 0 & -12 \\
$C_{m_{0}}$ & -8 & -13 & -7 & 88 & 9 & 84 & 99 & 100 & 0 & -13 \\
$\theta_{0}$ & 0 & 0 & 0 & 0 & 1 & -1 & 0 & 0 & 100 & 0 \\
$C_{N_{0}}$ & 62 & 98 & 65 & -10 & 1 & 2 & -12 & -13 & 0 & 100 \\
\hline
\end{tabular}

Based on the correlation coefficient matrix from RRR for this case with 10 unknown parameters the weakest can be inferred as $\theta_{0}$, which is almost uncorrelated with all other parameters. Hence its estimates and uncertainty can vary widely among the approaches. Next it is possible to group the parameters as $\left(C_{N_{0}}, C_{L_{\alpha}}, C_{L_{\delta_{e}}}, C_{L_{0}}\right)$ and $\left(C_{M_{0}}, C_{M_{\delta_{e}}}, C_{M_{\dot{\alpha}}}\right.$, $C_{M_{q}}, C_{M_{\alpha}}$ ). As mentioned earlier the estimation of the aerodynamic parameters depends on two factors, namely their representation and the excitation. Among the above group 4 and 5 parameters this feature should be kept in mind by a designer using the above estimates for further use. 


\section{Analysis of real flight test case-3}

The data set is obtained from NASA TP 1690, which describes the lateral motion of an oblique wing aircraft with zero wing skew excited by the control input $\left(\delta_{a}\right.$ and $\delta_{r}$ in deg) as shown in figure 23. Similar to the earlier case, the coupling between the longitudinal and lateral motion is replaced by their measured values, which includes pitch angle $\left(\theta_{m}\right.$ in rad), pitch rate $\left(q_{m}\right.$ in $\left.\mathrm{rad} / \mathrm{s}\right)$ and the angle of attack $\left(\alpha_{m}\right.$ in rad) as shown in figures 24,25 and 26, respectively. The state equations $(n=4)$ for the angle of sideslip $(\beta)$, roll rate $(p)$, roll angle $(\phi)$ and yaw rate $(r)$ are

$$
\begin{aligned}
\dot{\beta}= & \frac{\bar{q} S}{m V}\left(C_{Y_{\beta}} \beta+C_{Y_{p}} \frac{b}{2 V} p+C_{Y_{r}} \frac{b}{2 V} r+C_{Y_{\delta_{a}}} \delta_{a}+C_{Y_{\delta_{r}}} \delta_{r}+\beta_{0}\right) \\
& +\frac{g}{V} \sin (\phi) \cos \left(\theta_{m}\right)+p \sin \left(\alpha_{m}\right)-r \cos \left(\alpha_{m}\right) \\
\dot{p}- & \dot{r} \frac{I z x}{I x x}=\frac{\bar{q} S b}{I x x}\left(C_{L_{\beta}} \beta+C_{L_{p}} \frac{\bar{c}}{2 V} p+C_{L_{r}} \frac{\bar{c}}{2 V} r+C_{L_{\delta_{a}}} \delta_{a}+C_{L_{\delta_{r}}} \delta_{r}+C_{L_{0}}\right) \\
& +\frac{I y y-I z z}{I x x} r q_{m}+\frac{I z x}{I x x} p q_{m} \\
\dot{\phi} & =p+q \tan \left(\theta_{\mathrm{m}}\right) \sin (\phi)+\operatorname{rtan}\left(\theta_{\mathrm{m}}\right) \cos (\phi)+\phi_{0} \\
\dot{r}- & \dot{p} \frac{I z x}{I z z}=\frac{\bar{q} S b}{I z z}\left(C_{N_{\beta}} \beta+C_{N_{p}} \frac{b}{2 V} p+C_{N_{r}} \frac{b}{2 V} r+C_{N_{\delta_{a}}} \delta_{a}+C_{N_{\delta_{r}}} \delta_{r}+C_{N_{0}}\right) \\
& +\frac{I x x-I y y}{I z z} p q_{m}-\frac{I z x}{I z z} r q_{m} .
\end{aligned}
$$

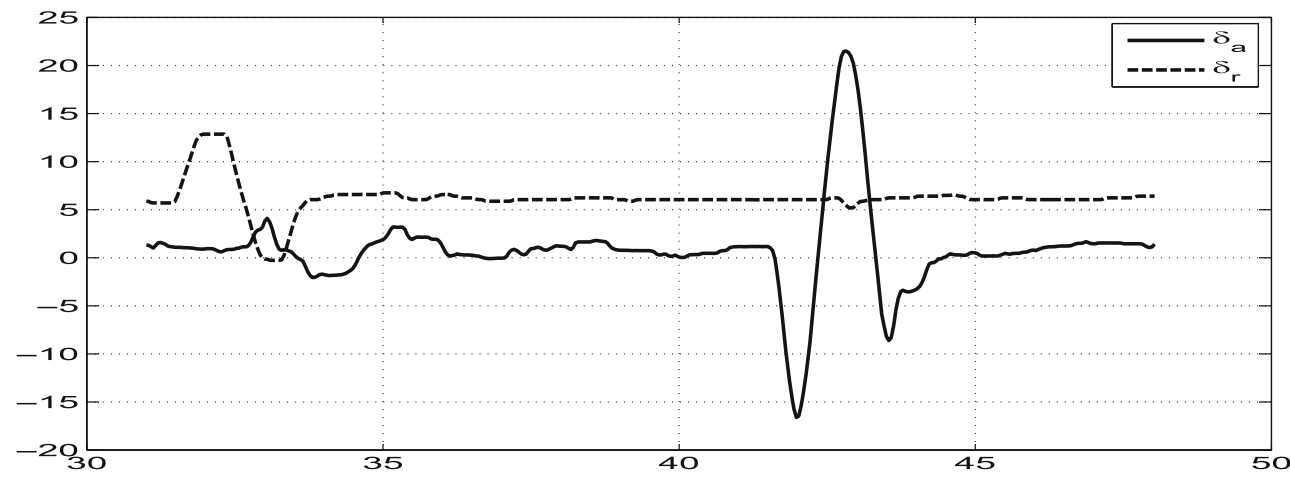

Figure 23. Control input $\left(\delta_{a}, \delta_{r}\right.$ in deg) versus time (s).

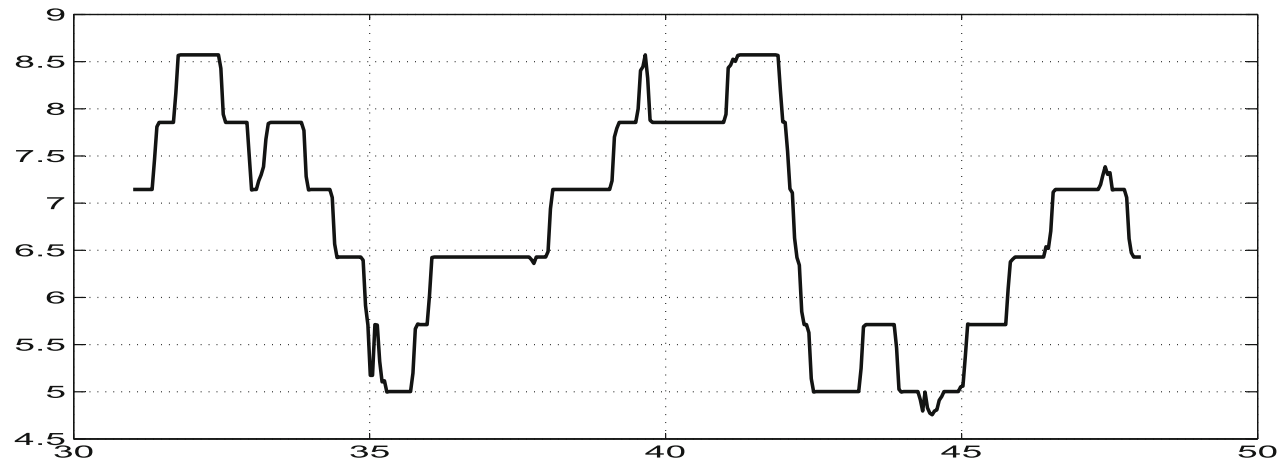

Figure 24. Input pitch angle $\left(\theta_{m}\right.$ in deg) versus time (s).

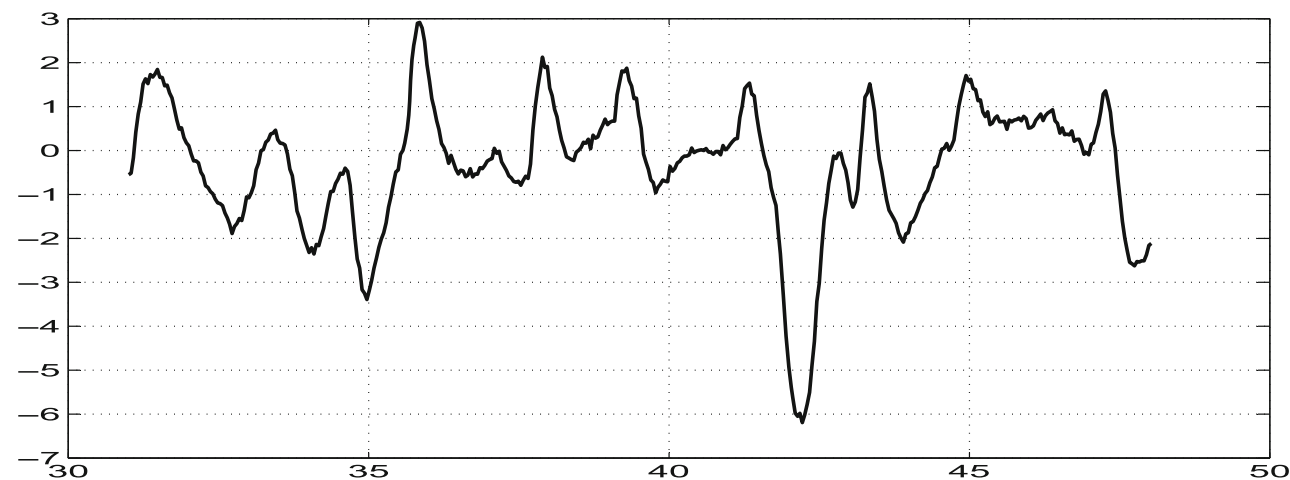

Figure 25. Input pitch rate $\left(q_{m}\right.$ in $\left.\mathrm{deg} / \mathrm{s}\right)$ versus time (s). 


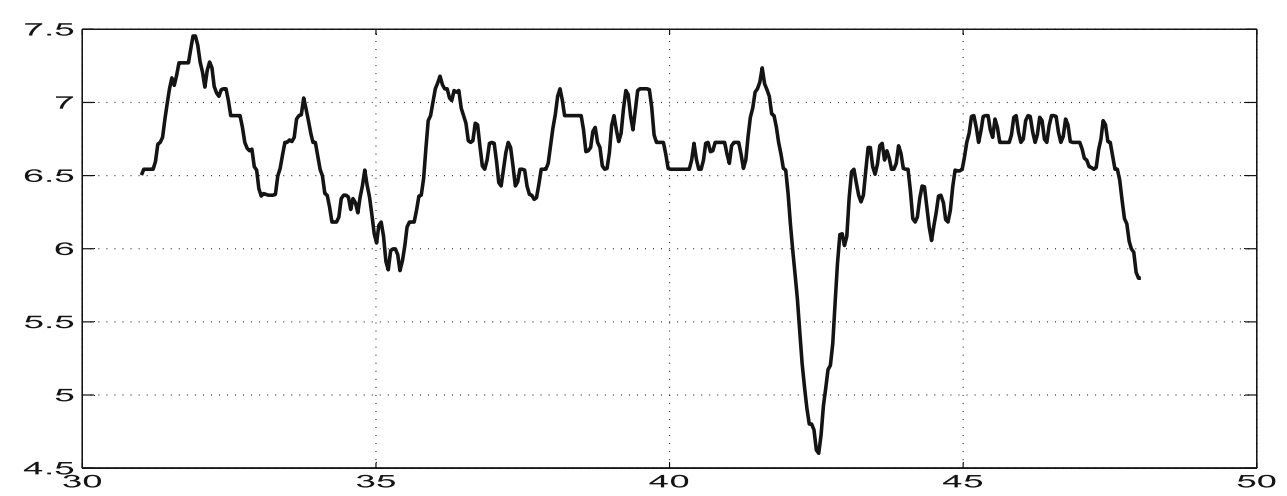

Figure 26. Input angle of attack $\left(\alpha_{m}\right.$ in deg) versus time (s).

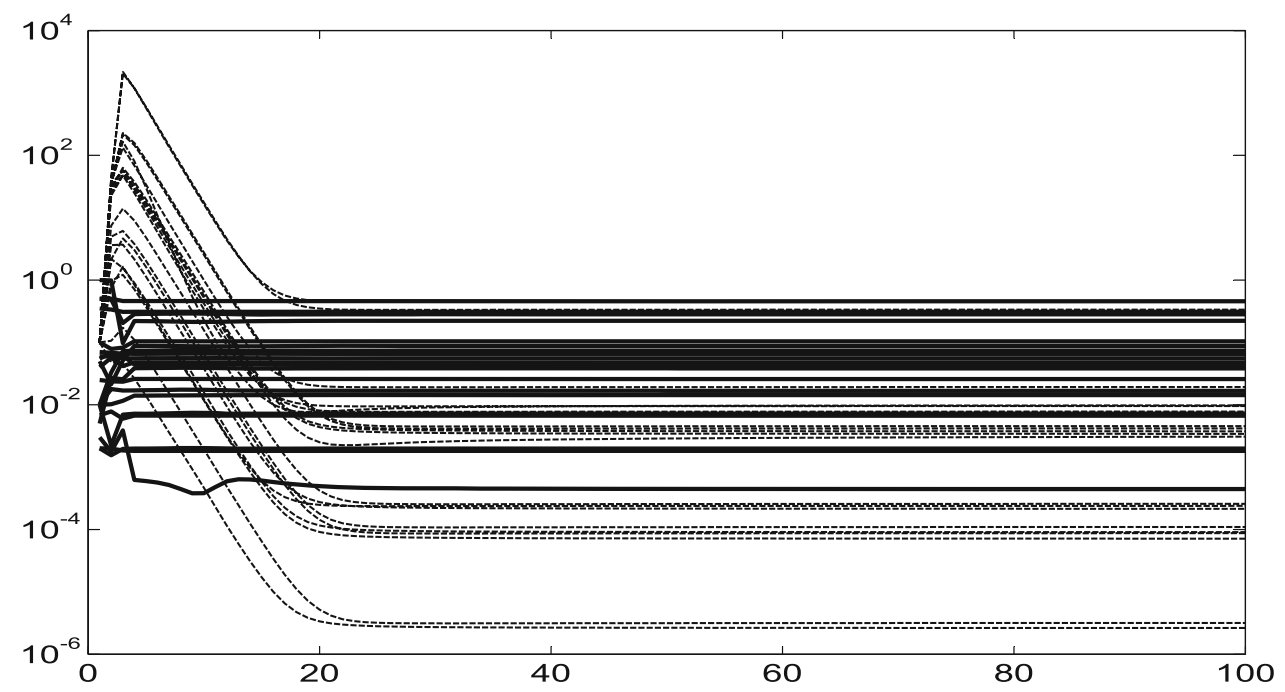

Figure 27. Variation of initial parameters $\Theta_{0}$ (continuous) and their $\mathbf{P}_{\mathbf{0}}$ (dashed) with iterations.

The measurement equations $(m=5)$ are given by

$$
\begin{aligned}
\beta_{m}= & \beta-K_{\beta} z_{\beta} \frac{p}{V}+K_{\beta} x_{\beta} \frac{r}{V} ; \quad p_{m}=p ; \quad \phi_{m}=\phi ; \quad r_{m}=r ; \\
a_{y_{m}}= & \frac{\bar{q} S}{m g}\left(C_{Y_{\beta}} \beta+C_{Y_{p}} \frac{b}{2 V} p+C_{Y_{r}} \frac{b}{2 V} r+C_{Y_{\delta_{a}}} \delta_{a}+C_{Y_{\delta_{r}}} \delta_{r}+C_{Y_{0}}\right) \\
& -\frac{z_{a_{y}}}{g} \dot{p}+\frac{x_{a_{y}}}{g} \dot{r} .
\end{aligned}
$$

The unknown parameter set $(p=20)$ is $\Theta=\left(C_{Y_{\beta}}, C_{Y_{\delta_{r}}}\right.$, $\beta_{0}, C_{L_{\beta}}, C_{L_{p}}, C_{L_{r}}, C_{L_{\delta_{a}}}, C_{L_{\delta_{r}}}, C_{L_{0}}, \phi_{0}, C_{N_{\beta}}, \quad C_{N_{p}}, \quad C_{N_{r}}, C_{N_{\delta_{a}}}$, $\left.C_{N_{\delta_{r}}}, C_{N_{0}}, C_{Y_{0}}, C_{Y_{p}}, C_{Y_{r}}, C_{Y_{\delta_{a}}}\right)^{\mathrm{T}}$. The ones with suffix ' $\delta_{a}$ ' and ' $\delta_{r}$ ' are the control derivatives, the ones with suffix zero are the biases and all others are aerodynamic derivatives. The initial states are taken as initial measurement and the initial parameter values are taken as $(-0.5,0.1,-0.01$, $0.01,-0.35,0.01,0.06,0.01,-0.002,0.002,0.07,-0.055$, $-0.05,0.003,-0.04,0.0068,-0.025,0.5,-1,0.005)^{T}$.
Other constant values used for case-3 are as follows:

\begin{tabular}{ccccccc}
\hline $\bar{q}=$ & $\mathrm{S}=$ & $\mathrm{m}=$ & $\mathrm{Ixx}=$ & $\mathrm{Iyy}=$ & $\mathrm{Izz}=$ & $\mathrm{Izx}=$ \\
865.3 & 9.3 & 387.7 & 314 & 488 & 698 & 69 \\
$\mathrm{~V}=$ & $\mathrm{g}=$ & $\mathrm{b}=$ & $K_{\beta} z_{\beta}=$ & $K_{\beta} x_{\beta}=$ & $z_{a_{y}}=$ & $x_{a_{y}}=$ \\
39.41 & 9.81 & 6.81 & 0.305 & 2.73 & -0.098 & 0.651 \\
\hline
\end{tabular}

\subsection{Remarks on the real data case-3 results}

Figures 23-26 show the inputs used in the state equations. The variations of the absolute value of the estimated initial parameters and their $\mathbf{P}_{\mathbf{0}}$ with iterations are shown in figure 27 and similarly in figure 28 for $\mathbf{Q}$ and $\mathbf{R}$ and in figure 29 for the cost functions J1-J8. Figures 30-32 compare the measurements with the (i) the state dynamics based on the estimated parameters, (ii) the state after measurement update and (iii) the smoothed state.

Table 5 provides a comparison of the parameter estimates along with their CRBs (in parenthesis) for all the real data studied by different approaches. Since the NASA and 


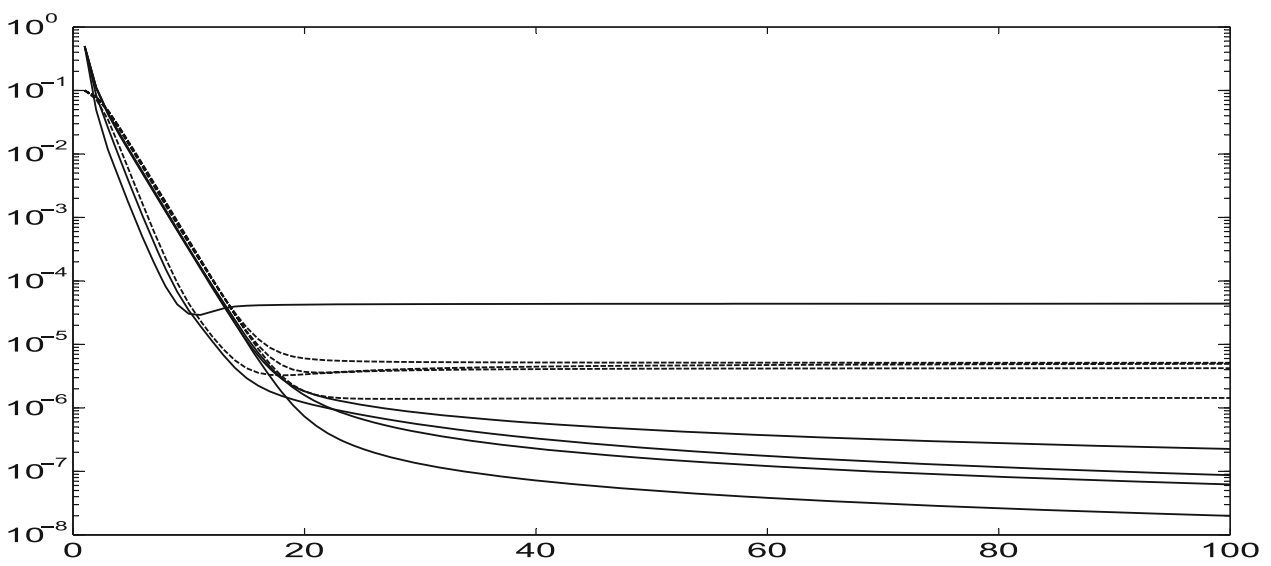

Figure 28. Variation of $\mathbf{Q}$ (dashed) and $\mathbf{R}$ (continuous) with iterations.

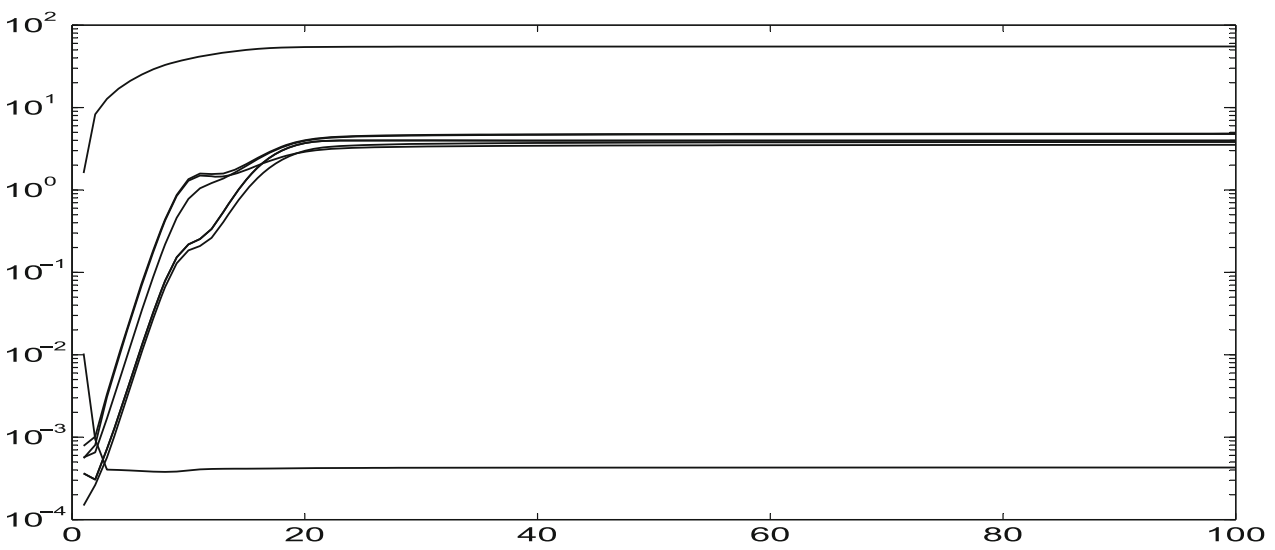

Figure 29. Variation of different costs $(\mathbf{J 1}-\mathbf{J 8})$ with iterations.

(a)

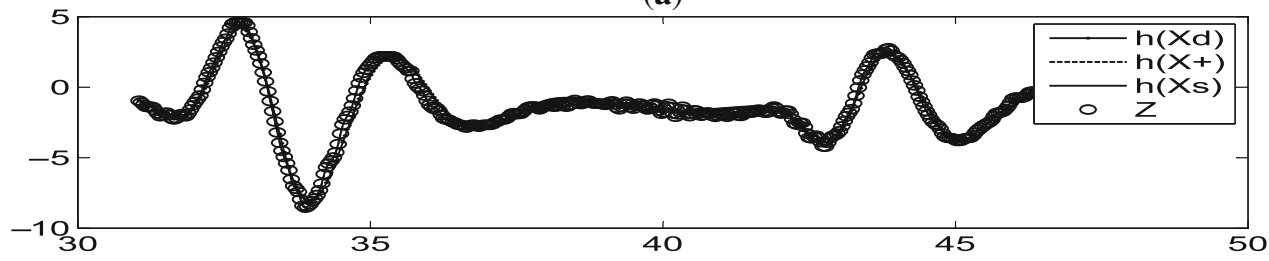

(b)

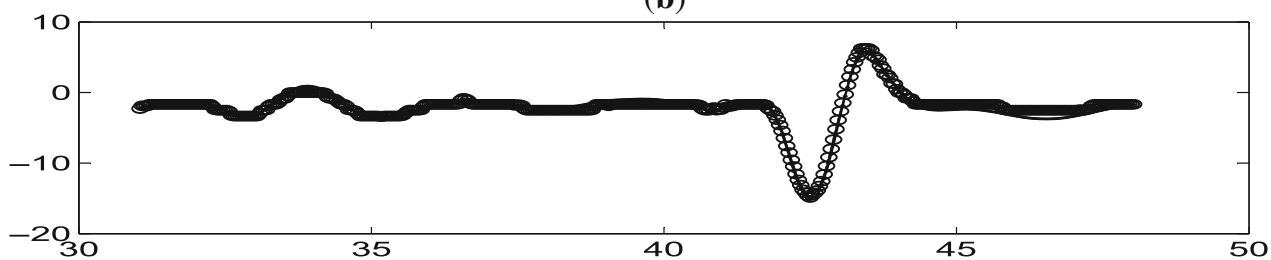

Figure 30. Comparison of the predicted dynamics, posterior, smoothed and the measurement in deg, (a) sideslip and (b) roll angle, versus time.

Gemson's results are obtained with $\mathbf{Q}=0$ and with fewer (17) parameters only a comparison with other approaches is valid. Generally the CRBs from the RRR is lower than from other approaches and at times their lower CRBs is only fortuitous. The rounded $100 C$ matrix of the parameter estimates is 


\begin{tabular}{|c|c|c|c|c|c|c|c|c|c|c|c|c|c|c|c|c|c|c|c|c|}
\hline$\Theta$ & $\beta_{0}$ & $\phi_{0}$ & $C_{L_{\beta}}$ & $C_{L_{p}}$ & $C_{L_{r}}$ & $C_{L_{\delta_{0}}}$ & $C_{L_{\delta_{r}}}$ & $C_{L_{0}}$ & $C_{N_{\beta}}$ & $C_{N_{p}}$ & $C_{N_{r}}$ & $C_{N_{\delta_{a}}}$ & $C_{N_{\delta_{\gamma_{n}}}}$ & $C_{N_{0}}$ & $C_{Y_{\beta}}$ & $C_{Y_{p}}$ & $C_{Y_{r}}$ & $C_{Y_{\delta_{a}}}$ & $C_{Y_{\delta_{r}}}$ & $C_{Y_{0}}$ \\
\hline$\beta_{0}$ & 100 & -1 & 0 & 0 & 0 & 0 & 1 & 0 & 0 & 0 & 2 & 0 & 4 & -8 & 3 & 0 & -9 & -1 & -15 & 16 \\
\hline$\phi_{0}$ & -1 & 100 & 0 & 0 & 0 & 0 & 0 & 0 & 0 & 0 & 0 & 0 & 0 & 0 & 0 & 0 & 0 & 0 & 0 & 0 \\
\hline$C_{L_{\beta}}$ & 0 & 0 & 100 & 17 & 12 & -11 & 3 & 12 & -28 & -5 & -3 & 3 & -1 & -3 & -6 & -1 & -1 & 1 & 0 & -1 \\
\hline$C_{L_{p}}$ & 0 & 0 & 17 & 100 & 3 & -84 & 8 & 1 & -5 & -29 & -1 & 24 & -2 & 0 & -1 & -5 & 0 & 4 & 0 & 0 \\
\hline$C_{L_{r}}$ & 0 & 0 & 12 & 3 & 100 & -2 & 62 & -57 & -3 & -1 & -28 & 0 & -17 & 16 & -1 & 0 & -6 & 0 & -4 & 3 \\
\hline$C_{L_{\delta_{\delta}}}$ & 0 & 0 & -11 & -84 & -2 & 100 & -3 & -6 & 3 & 24 & 0 & -29 & 1 & 2 & 1 & 4 & 0 & -5 & 0 & 0 \\
\hline$C_{L_{\delta_{r}}}$ & 1 & 0 & 3 & 8 & 62 & -3 & 100 & -96 & -1 & -2 & -17 & 1 & -29 & 27 & 0 & 0 & -4 & 0 & -6 & 6 \\
\hline$C_{L_{0}}$ & 0 & 0 & 12 & 1 & -57 & -6 & -96 & 100 & -3 & 0 & 16 & 2 & 27 & -29 & -1 & 0 & 3 & 0 & 6 & -6 \\
\hline$C_{N_{\beta}}$ & 0 & 0 & -28 & -5 & -3 & 3 & -1 & -3 & 100 & 17 & 12 & -11 & 3 & 12 & -27 & -4 & -3 & 3 & -1 & -3 \\
\hline$C_{N_{p}}$ & 0 & 0 & -5 & -29 & -1 & 24 & -2 & 0 & 17 & 100 & 3 & -84 & 8 & 1 & -5 & -22 & -1 & 19 & -2 & 0 \\
\hline$C_{N_{r}}$ & 2 & 0 & -3 & -1 & -28 & 0 & -17 & 16 & 12 & 3 & 100 & -2 & 62 & -57 & -3 & -1 & -27 & 0 & -16 & 15 \\
\hline$C_{N_{\delta_{s}}}$ & 0 & 0 & 3 & 24 & 0 & -29 & 1 & 2 & -11 & -84 & -2 & 100 & -3 & -6 & 3 & 19 & 0 & 22 & 1 & 2 \\
\hline$C_{N_{\delta_{s_{n}}}}$ & 4 & 0 & -1 & -2 & -17 & 1 & -29 & 27 & 3 & 8 & 62 & -3 & 100 & -96 & -1 & -2 & -17 & 1 & -26 & 25 \\
\hline$C_{N_{r}}$ & -8 & 0 & -3 & 0 & 16 & 2 & 27 & -29 & 12 & 1 & -57 & -6 & -96 & 100 & -3 & 0 & 15 & 1 & 25 & -26 \\
\hline$C_{Y_{\beta}}$ & 3 & 0 & -6 & -1 & -1 & 1 & 0 & -1 & -27 & -5 & -3 & 3 & -1 & -3 & 100 & 21 & 7 & -16 & -3 & 18 \\
\hline$C_{Y_{p}}$ & 0 & 0 & -1 & -5 & 0 & 4 & 0 & 0 & -4 & -22 & -1 & 19 & -2 & 0 & 21 & 100 & 3 & -90 & 9 & 3 \\
\hline$C_{Y_{r}}$ & -9 & 0 & -1 & 0 & -6 & 0 & -4 & 3 & -3 & -1 & -27 & 0 & -17 & 15 & 7 & 3 & 100 & -2 & 64 & -60 \\
\hline$C_{Y_{\delta_{a}}}$ & -1 & 0 & 1 & 4 & 0 & -5 & 0 & 0 & 3 & 19 & 0 & -22 & 1 & 1 & -16 & -90 & -2 & 100 & -5 & -7 \\
\hline$C_{Y_{\delta_{s_{r}}}}$ & -15 & 0 & 0 & 0 & -4 & 0 & -6 & 6 & -1 & -2 & -16 & 1 & -26 & 25 & -3 & 9 & 64 & -5 & 100 & -96 \\
\hline$C_{Y_{0}}$ & 16 & 0 & -1 & 0 & 3 & 0 & 6 & -6 & -3 & 0 & 15 & 2 & 25 & -26 & 18 & 3 & -60 & -7 & -96 & 100 \\
\hline
\end{tabular}

(a)

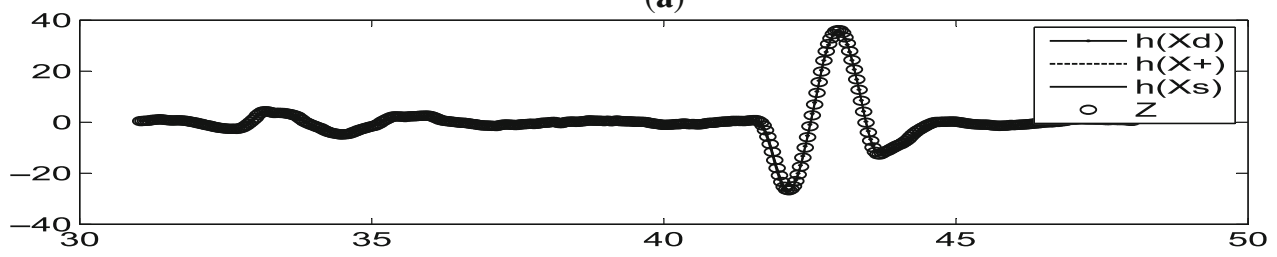

(b)

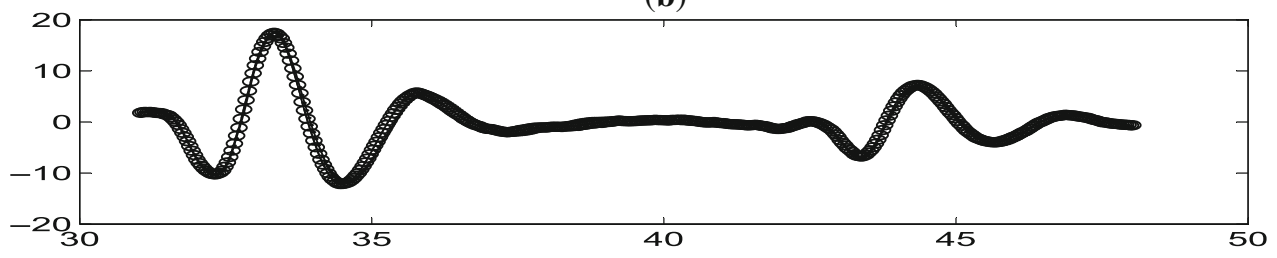

Figure 31. Comparison of the predicted dynamics, posterior, smoothed and the measurement in deg/s, (a) roll rate and (b) Yaw rate, versus time.

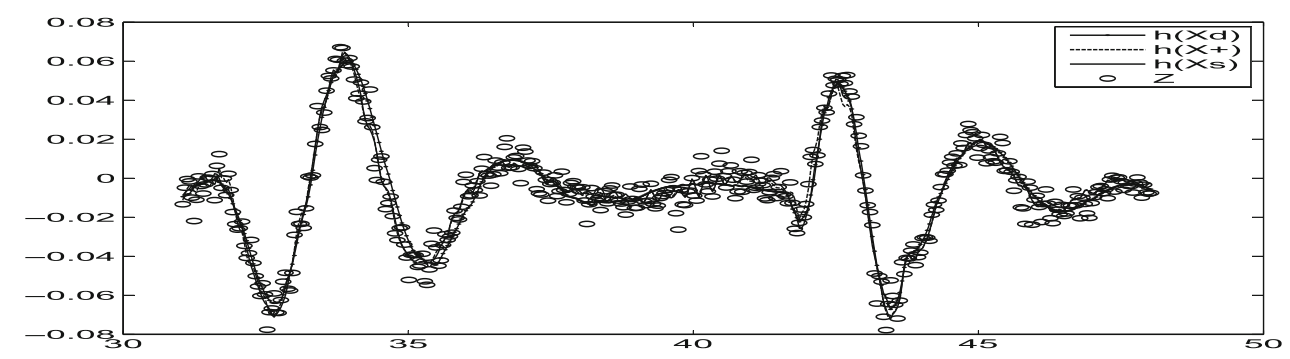

Figure 32. Comparison of the predicted dynamics, posterior, smoothed and the measurement in $g$ (lateral acceleration) versus time.

Based on the correlation coefficient matrix from RRR for this case with 20 unknown parameters the weakest can be inferred as $\beta_{0}$ and $\phi_{0}$, which are almost uncorrelated with all other parameters. Hence their estimates and uncertainty can vary widely among the approaches. Next it is possible to group the parameters into three sets as the parameters in the three sets $\left(C_{L_{\beta}}, C_{L_{p}}, C_{L_{r}}, C_{L_{\delta_{a}}}, C_{L_{\delta_{r}}}, C_{L_{0}}\right),\left(C_{N_{\beta}}, C_{N_{p}}, C_{N_{r}}\right.$, $\left.C_{N_{\delta_{a}}}, C_{N_{\delta_{r}}}, C_{N_{0}}\right)$ and $\left(C_{Y_{\beta}}, C_{Y_{p}}, C_{Y_{r}}, C_{Y_{\delta_{a}}}, C_{Y_{\delta_{r}}}, C_{Y_{0}}\right)$, All have very similar correlations among themselves as seen in the thick blocks of matrices and the reason is as follows. There is coupling of the dynamical motion due to the states and the controls. If a certain state or control is excited relatively higher than others then the estimated parameter that multiplies it will have lower correlation with other estimates in the set and vice versa. Since the parameter sets are similarly excited all of them have similar correlation coefficient matrices. As mentioned earlier the estimation of the 
aerodynamic parameters depends on two factors, namely their representation and the excitation. Among the above group of six parameters this feature should be kept in mind by a designer using the above estimates for further use.

\section{Conclusions}

The reference recursive recipe (RRR) is applied to the more involved cases of three sets of real airplane flight test data, which have a larger number of unknowns. A closer look at the correlation coefficients in such studies of estimating the unknown parameters indicates the necessity of processing the data by including the process noise $\mathbf{Q}$ in addition to the measurement noise R. Generally the parameter estimates across the various approaches are close but their CRB can vary much more among them. In particular the generalized cost functions based on balancing the state and measurement equations using the many filter outputs introduced in the present work help show the RRR to be more reliable than the earlier approaches.

\section{Acknowledgements}

Our grateful thanks are due to Profs R M Vasu (Department of Instrumentation and Applied Physics), D Roy (Department of Civil Engineering) and $M \quad R$ Muralidharan (Supercomputer Education and Research Centre) for help in a number of ways without which this work would just not have been possible at all and also for providing computational facilities at IISc, Bangalore.

\section{References}

[1] Schultz G 1976 Maximum Likelihood Identification Using Kalman Filtering Least Square Estimation. NTIS : N7630227/2, ESA TT-258

[2] Stepner D E and Mehra R K 1973 Maximum likelihood identification and optimal input design for identifying aircraft stability and control derivatives. NASA Contractor Report No. NASA CR-2200

[3] Maine R E and Iliff K W 1981 Programmer's manual for $M M L E 3$, a general Fortran program for maximum likelihood parameter estimation. NASA TP-1690

[4] Maine R E and Iliff K W 1981 Formulation and implementation of a practical algorithm for parameter estimation with process and measurement noise. SIAM J. Appl. Math., 41(3): $558-579$

[5] Jategaonkar R V and Plaetschke E 1989 Algorithms for aircraft parameter estimation accounting for process and measurement noise. J. Aircraft 26(4): 360-372

[6] Ishimoto S 1997 New algorithm of maximum likelihood parameter estimation for flight vehicles. AIAA-97-3784, pp. $791-801$

[7] Gemson R M O 1991 Estimation of aircraft aerodynamic derivatives accounting for measurement and process noise by EKF through adaptive filter tuning. $\mathrm{PhD}$ Thesis, Department of aerospace engineering, IISc, Bangalore

[8] Klein V and Morelli E A 2006 Aircraft system identification: theory and practice. In: AIAA Education Series

[9] Klein V 1979 Identification evaluation methods: parameter identification. AGARD-LS-104, pp. 2-21

[10] Jategaonkar R V 2006 Flight vehicle system identification: a time domain methodology. Volume 216, AIAA.

[11] Myers K A, Tapley B D 1976 Adaptive sequential estimation with unknown noise statistics. IEEE Trans. Autom. Control AC 21: 520-525

[12] Mohamed A H and Schwarz K P 1999 Adaptive Kalman filtering for INS/GPS. J. Geodesy 73(4): 193-203

[13] Shyam M M, Naren Naik, Gemson R M O and Ananthasayanam M R 2015 Introduction to the Kalman filter and tuning its statistics for near optimal estimates and cramer rao bound. TR/EE2015/401, Department of Electrical Engineering, IIT Kanpur, http://arxiv.org/abs/1503.04313

[14] Bohlin T 1976 Four cases of identification of changing systems. In: System identification: advances and case studies. Academic Press, 1st edition

[15] Gemson R M O and Ananthasayanam M R 1998 Importance of initial state covariance matrix for the parameter estimation using adaptive extended Kalman filter. AIAA-98-4153, pp. $94-104$

[16] Shafer M F 1975 Stability and control derivatives of the $T-37 B$ airplane. NASA TM X-56036 